Article

\title{
Crosslinking Behavior of UV-Cured Polyorganosilazane as Polymer-Derived Ceramic Precursor in Ambient and Nitrogen Atmosphere
}

\author{
Afnan Qazzazie-Hauser ${ }^{1, *(\mathbb{D})}$, Kirsten Honnef ${ }^{1}$ and Thomas Hanemann ${ }^{1,2, * \mathbb{D}}$ \\ 1 Laboratory for Materials Processing, Department of Microsystems Engineering, University of Freiburg, \\ 79110 Freiburg, Germany; kirsten.honnef@imtek.uni-freiburg.de \\ 2 Institute for Applied Materials, Karlsruhe Institute of Technology (KIT), Hermann-von-Helmholtz-Platz 1, \\ 76344 Eggenstein-Leopoldshafen, Germany \\ * Correspondence: afnan.qazzazie@imtek.uni-freiburg.de (A.Q.-H.); thomas.hanemann@kit.edu (T.H.); \\ Tel.: +49-761-203-7556 (A.Q.-H.)
}

check for updates

Citation: Qazzazie-Hauser, A.; Honnef, K.; Hanemann, T. Crosslinking Behavior of UV-Cured Polyorganosilazane as

Polymer-Derived Ceramic Precursor in Ambient and Nitrogen Atmosphere. Polymers 2021, 13, 2424. https://doi.org/10.3390/ polym 13152424

Academic Editor: Emanuel Ionescu

Received: 20 June 2021

Accepted: 19 July 2021

Published: 23 July 2021

Publisher's Note: MDPI stays neutra with regard to jurisdictional claims in published maps and institutional affiliations.

Copyright: (c) 2021 by the authors. Licensee MDPI, Basel, Switzerland. This article is an open access article distributed under the terms and conditions of the Creative Commons Attribution (CC BY) license (https:// creativecommons.org/licenses/by/ $4.0 /)$
Abstract: Polymer-derived ceramics (PDCs) based on silicon precursor represent an outstanding material for ceramic coatings thanks to their extraordinary versatile processibility. A promising example of a silicone precursor, polyorganosilazane (Durazane 1800), was studied concerning its crosslinking behavior by mixing it with three different photoinitiators, and curing it by two different UV-LED sources under both nitrogen and ambient atmosphere. The chemical conversion during polymerization and pyrolysis was monitored by FTIR spectroscopy. Pyrolysis was performed in a nitrogen atmosphere at $950{ }^{\circ} \mathrm{C}$. The results demonstrate that polyorganosilazane can be cured by the energy-efficient UV-LED source at room temperature in nitrogen and ambient atmosphere. In nitrogen atmosphere, already common reactions for polysilazanes, including polyaddition of the vinyl group, dehydrogenation reactions, hydrosilylation, and transamination reaction, are responsible for crosslinking. Meanwhile, in ambient atmosphere, hydrolysis and polycondensation reactions occur next to the aforementioned reactions. In addition, the type of photoinitiator has an influence on the conversion of the reactive bonds and the chemical composition of the resulting ceramic. Furthermore, thermogravimetric analysis (TGA) was conducted in order to measure the ceramic yield of the cured samples as well as to study their decomposition. The ceramic yield was observed in the range of 72 to $78 \%$ depending on the composition and the curing atmosphere. The curing atmosphere significantly impacts the chemical composition of the resulting ceramics. Depending on the chosen atmosphere, either silicon carbonitride $(\mathrm{SiCN})$ or a partially oxidized $\mathrm{SiCN}(\mathrm{O})$ can be produced.

Keywords: polysilazane; crosslinking; UV-LED photopolymerization; preceramic polymers; FTIR spectroscopy

\section{Introduction}

In recent years, polymer-derived ceramics (PDCs) based on silicon precursor such as polyorganosilazane have been used as precursors for ceramics [1], as they offer many advantageous properties, in particular excellent adhesion on numerous surfaces [2,3] as well as high thermal and chemical stability [4]. In addition, polysilazane serves as a component for the preparation of ceramic matrix composites produced by means of additive manufacturing $[5,6]$. Polyorganosilazane consists of an alternating silicon and nitrogen backbone and is produced on a large scale via ammonolysis of dichlorosilane $\left(\mathrm{R}_{2} \mathrm{SiCl}_{2}\right)[7,8]$. Like polymers, PDCs benefit from the extraordinary versatility of processing when compared with bulk ceramics. After processing, it is necessary to perform crosslinking followed by pyrolysis, leading to the desired ceramic. The crosslinking can be conducted thermally by adding a free radical initiator such as peroxides [9-11], catalysts [12], or photochemically [13-15], to form an infusible network. Another well-established method for the 
crosslinking of polysilazane and other PDCs is the thiol-ene click chemistry, which is also induced by means of UV light [16-18]. Thereby, the polymerization can occur by the addition of the thiol group to the vinyl group of polysilazane, which modifies the compound completely. Owing to the step-growth polymerization, the gelation happens when a high amount of functional groups has reacted [16].

UV-curing is a well-known fast and low-cost method for the fabrication of polymers $[19,20]$ and can be perfomed at room temperature. Preliminary, UV-curing of polysilazane has been realized before by applying photoinitiators absorbing in the UV-C region [21,22]. Typically, the UV light source for this range is an environmentally harmful mercury-vapor lamp, as it delivers light in the $280-450 \mathrm{~nm}$ range, matching the absorption of the photoinitatiors [23]. In other works, polysilazane has been synthetically modified by mixing it with acrylates, resulting in a photocurable resin, which was cured by digital light processing [6,14]. The photoinitiator 2,2-dimethoxy-2-phenyl acetophenone, which has its absorbance maximum between 310 and $390 \mathrm{~nm}$ [24], was used by the authors $\mathrm{Hu}$ et al. [25] to cure polysilazane into free standing specimen (138 and $38 \mu \mathrm{m})$ followed by thermal deep curing. Another scientist used the same photoinitiator for the fabrication of SiCN MEMS [26]. In comparison with this work, the authors focus on the characterization of the material properties after the pyrolysis process and less on the crosslinking behavior of polysilazane.

In this work, the UV-curing approach was adopted, replacing the mercury-vapor lamp by the energy-efficient UV-LED source [20], to start the crosslinking reaction by free-radical polymerization.

The material presented here is a low-viscous and colorless polyorganosilazane, which has excellent adhesion properties to most surfaces. Therefore, it is used as coating material processed by spin- or dip-coating [3,27]. The solubility in most organic solvents and the resulting tailoring in viscosity make the material attractive for usage as binding material for filler-loaded preceramic polymer [28,29]. In inert atmosphere, the crosslinked network of polysilazane can be pyrolyzed into amorphous silicon carbonitride $(\mathrm{SiCN})$ at a temperature of $800^{\circ} \mathrm{C}$, whereas at temperatures higher than $1400^{\circ} \mathrm{C}$, it crystallizes and phase separates into silicon nitride and silicon carbide $[1,30,31]$.

The aim of this work is to investigate the crosslinking behavior of polyorganosilazane cured by ultraviolet light emitting diode (UV-LED) sources inducing the free-radical polymerization of different photoinitiators. The photoinitiators used are benzophenone derivate: dibenzosuberone (DBS), 4-(dimethylamino) benzophenone (DMABP), and isopropylthioxanthone (ITX). The crosslinking behavior of the mixtures was analyzed in detail before and after curing by FTIR spectroscopy. Furthermore, after the photo-polymerization process, the samples were pyrolyzed at $950{ }^{\circ} \mathrm{C}$. The structure of the amorphous ceramics and the resulting ceramic yield and the decomposition behavior were investigated by FTIR spectroscopy and thermogravimetric analysis, respectively.

\section{Materials and Methods}

\subsection{Materials}

The compound utilized in this research is a commercially available liquid preceramic polymer, organopolysilazane (OPSZ, Durazane 1800, Merck KGaA, Darmstadt, Germany). The polymer consists of a silicon and nitrogen backbone, which is functionalized with different side groups, e.g., hydrogen, methyl, and vinyl groups. The simplified chemical structures are presented in Figure 1. 
<smiles>[R7]C(C)(C)N1C([R])(C)C[Si]1(C)C</smiles>

(a)<smiles>CC1(C)C[PH](C)(C)NC1(C)C</smiles>

(b)<smiles>C=C[Si](C)(C)N(C)C(C)(C)C</smiles>

(c)

Figure 1. (a) Chemical structure of Durazane 1800 with $\mathrm{R}_{1}, \mathrm{R}_{2}$, and $\mathrm{R}_{3}$, which are usually $\mathrm{H}, \mathrm{CH}_{3}$, or $\mathrm{CH}=\mathrm{CH}_{2}$ bonds, respectively, demonstrated in the chemical structures $(\mathbf{b}, \mathbf{c})$.

Three different photoinitiators, dibenzosuberone (DBS, purity $98 \%$, Merck KGaA, Darmstadt, Germany), 4-(dimethylamino)benzophenone (DMABP, purity 99\%, Merck $\mathrm{KGaA}$, Darmstadt, Germany), and isopropylthioxanthone (Genocure ITX, purity $>98.0 \%$, Rahn AG, Zürich, Switzerland) (Figure 2), were added to Durazane 1800 in order to investigate its curing behavior. All photoinitiators are derivates of benzophenone. 2-propanol (Carl Roth, 99.9\%, Karlsruhe, Germany) was used as a solvent.<smiles>O=c1c2ccccc2ccc2ccccc12</smiles>

(a)<smiles>CN(C)c1ccc(C(=O)c2ccccc2)cc1</smiles>

(b)<smiles>CC(C)c1cccc2c(=O)c3ccccc3sc12</smiles>

(c)

Figure 2. Photoinitiators used: (a) dibenzosuberonene (DBS), (b) 4-(dimethylamino)benzophenone (DMABP), and (c) isopropylthioxanthone (ITX).

\subsection{Preparation and Characterization}

In a first series of experiments, the preceramic polymer Durazane 1800 was mixed with three different photoinitiators to obtain photosensitive mixtures (see Table 1) and to investigate the polymerization behavior.

Each photoinitiator $(1 \mathrm{wt} \%$ or $3 \mathrm{wt} \%)$ was dissolved in Durazane $1800(100 \mathrm{wt} \%)$ using a high shear disperser (T-10 basic Ultra-Turrax ${ }^{\circledR}$, IKA, Germany) for $120 \mathrm{~s}$ at $9400 \mathrm{rpm}$. After the dissolution of the photoinitiator in Durazane 1800, the samples were irradiated for 300 s with LED light sources (LED-Spot-100 lamp, Dr. Hönle UV Technology, München, Germany) with different wavelengths (385 and $405 \mathrm{~nm}$ ) in ambient $(47 \% \mathrm{RH})$ or nitrogen atmosphere $(1.1 \% \mathrm{RH})$. The relative humidity $(\mathrm{RH})$ inside the $\mathrm{UV}$ chamber was measured by testo $608-\mathrm{H} 2$ thermo hygrometer (Testo SE \& Co. KGaA, Titisee-Neustadt, Germany). The intensity $\mathrm{I}_{0}$ of the UV lamps $(\lambda=385$ or $405 \mathrm{~nm})$ was $569 \mathrm{~mW} / \mathrm{cm}^{2}$ and $553 \mathrm{~mW} / \mathrm{cm}^{2}$, 
respectively. The intensity values were measured by the UV-Meter (HighEnd, Dr. Hönle UV Technology, Gräfelfing, Germany).

Table 1. Overview of the sample description with respect to the used UV lamp and atmosphere as parameters for the polymerization process. All mixtures contain $100 \mathrm{wt} \%$ Durazane 1800 and were cured for $300 \mathrm{~s}$.

\begin{tabular}{cccccc}
\hline & & & & \multicolumn{2}{c}{ Polymerization } \\
\cline { 5 - 6 } Sample & Initiator & $\begin{array}{c}\mathbf{c} \\
\text { (Initiator) } \\
\text { [wt } \% \text { ] }\end{array}$ & $\begin{array}{c}\text { (Initiator) } \\
\text { (mol/L) }\end{array}$ & $\begin{array}{c}\text { UV Lamp } \\
\text { [nm] }\end{array}$ & Atmosphere \\
\hline DBS01 & DBS & 1 & $1.6 \times 10^{-2}$ & 385 & Ambient \\
DBS02 & DBS & 3 & $4.8 \times 10^{-2}$ & 385 & Ambient \\
DBS03 & DBS & 1 & $1.6 \times 10^{-2}$ & 385 & $\mathrm{~N}_{2}$ \\
DBS04 & DBS & 3 & $4.8 \times 10^{-2}$ & 385 & $\mathrm{~N}_{2}$ \\
\hline DMABP01 & DMABP & 1 & $1.5 \times 10^{-2}$ & 385 & Ambient \\
DMABP02 & DMABP & 3 & $4.4 \times 10^{-2}$ & 385 & Ambient \\
DMABP03 & DMABP & 1 & $1.5 \times 10^{-2}$ & 385 & $\mathrm{~N}_{2}$ \\
DMABP04 & DMABP & 3 & $4.4 \times 10^{-2}$ & 385 & $\mathrm{~N}_{2}$ \\
DMABP05 & DMABP & 1 & $1.5 \times 10^{-2}$ & 405 & Ambient \\
DMABP06 & DMABP & 3 & $4.4 \times 10^{-2}$ & 405 & Ambient \\
DMABP07 & DMABP & 1 & $1.5 \times 10^{-2}$ & 405 & $\mathrm{~N}_{2}$ \\
DMABP08 & DMABP & 3 & $4.4 \times 10^{-2}$ & 405 & $\mathrm{~N}_{2}$ \\
\hline ITX01 & ITX & 1 & $1.3 \times 10^{-2}$ & 385 & Ambient \\
ITX02 & ITX & 3 & $3.9 \times 10^{-2}$ & 385 & Ambient \\
ITX03 & ITX & 1 & $1.3 \times 10^{-2}$ & 385 & $\mathrm{~N}_{2}$ \\
ITX04 & ITX & 3 & $3.9 \times 10^{-2}$ & 385 & $\mathrm{~N}_{2}$ \\
ITX05 & ITX & 1 & $1.3 \times 10^{-2}$ & 405 & Ambient \\
ITX06 & ITX & 3 & $3.9 \times 10^{-2}$ & 405 & Ambient \\
ITX07 & ITX & 1 & $1.3 \times 10^{-2}$ & 405 & $\mathrm{~N}_{2}$ \\
ITX08 & ITX & 3 & $3.9 \times 10^{-2}$ & 405 & $\mathrm{~N}_{2}$ \\
\hline
\end{tabular}

The Fourier-transform infrared (FT-IR) spectrometer was conducted to investigate the crosslinking behavior of the material. The spectra of all samples were recorded within a wavenumber range of 4000 and $500 \mathrm{~cm}^{-1}$ by averaging 32 scans at a resolution of $4 \mathrm{~cm}^{-1}$ using a Bio-Rad FTS 3000 Excalibur spectrometer (Varian, Palo Alto, CA, USA). The samples were coated with a doctor blade onto a shiny etched silicon wafer $(\sim 600 \mu \mathrm{m})$ and measured both uncured and UV-cured. The thickness of the samples on the silicon wafer was about $2 \mu \mathrm{m}$. A background measurement of a blank silicon wafer was taken first and substracted from each measured spectra.

The pyrolysis was performed in an alumina tube furnace (Carbolite, Neuhausen, Germany) at $950{ }^{\circ} \mathrm{C}$, because the wafer is not resistant to higher temperatures. The heating rate was set at $1{ }^{\circ} \mathrm{C} / \mathrm{min}$ and the temperature was held for $1 \mathrm{~h}$ at $950{ }^{\circ} \mathrm{C}$ using a nitrogen flow rate of $120 \mathrm{~mL} / \mathrm{min}$. Because of the different coefficient of thermal expansion of silicon compared with the resulting amorphous $\operatorname{SiCN}(\mathrm{O})$, the pyrolysis temperature was set to $950{ }^{\circ} \mathrm{C}$ to avoid cracks in the layer on the wafer.

The absorption spectra of the photoinitiators were measured by a UV-VIS spectrometer (Cary 500 Bio, Varian, Palo Alto, CA, USA) within a wavelength range of 450 and $220 \mathrm{~nm}$. The photoinitiators were diluted in 2-propanol, filled into a quarz cuvette, and measured by dual-beam mode.

Thermogravimetric analysis (TGA) was performed using STA-409C (Netzsch Group $\mathrm{GmbH} \& \mathrm{Co}$, Selb, Germany) to evaluate the polymer-to-ceramic conversion behavior and to examine the residual ceramic yield of all samples. Around $300 \mu \mathrm{L}$ of each mixture was placed on a specimen and then the cured sample was scraped from the specimen. Around $20 \mathrm{mg}$ of each cured sample was heated up to $1200^{\circ} \mathrm{C}$ using a heating rate of $10^{\circ} \mathrm{C} / \mathrm{min}$ 
and a nitrogen flow rate of $100 \mathrm{~mL} / \mathrm{min}$. The experimental uncertainty for the residual mass measured by TGA is around $\pm 1 \%$.

\subsection{Degree of Conversion of the Reactive Bonds in Durazane 1800}

FTIR spectroscopy was used to determine the relative degree of conversion DC (\%) of Durazane 1800 and the photoinitiator after curing.

The degree of conversion was calculated using Equation (1) [32] for the chemical groups, which undergo chemical reactions during the crosslinking process: $\equiv \mathrm{Si}-\mathrm{H}, \mathrm{N}-\mathrm{H}$, and the vinyl group.

$$
\mathrm{DC}(\%)=\left(1-\frac{\mathrm{A}_{\mathrm{t}}}{\mathrm{A}_{0}}\right) \times 100
$$

Thereby, the content of the integrated peak areas of the reactive bonds of the cured samples was defined as $A_{t}$. The content of the reactive bond of the uncured sample, which was defined as $A_{0}$, was taken as $100 \%$. To minimize the influence of deviations in sample thickness and instrument recording, all integrals were normalized by the integral of the $\mathrm{Si}-\mathrm{CH}_{3}$ bond at $1253 \mathrm{~cm}^{-1}$, as this bond does not change throughout the whole crosslinking process.

\subsection{Crosslinking Mechanism of Polysilazane}

Curing of preceramic polymers, such as Durazane 1800, usually takes place thermally by the addition of a free radical initiator like peroxides or catalysts. In this work, this approach was adopted, replacing the high temperature with the energy-efficient LED source to start the crosslinking reaction. Hence, as indicated before, three different photoinitiators were used for the polymerization of Durazane 1800.

All used photoinitiators are derivates of benzophenone, which are Norrish type II photoinitiators [33], meaning that, when irradiated with UV light, they are excited to the singlet state, which subsequently changes to the triplet state via intersystem crossing (ISC) [34]. The mechanism is schematically illustrated in Figure 3 for the photoinitiator DMABP.

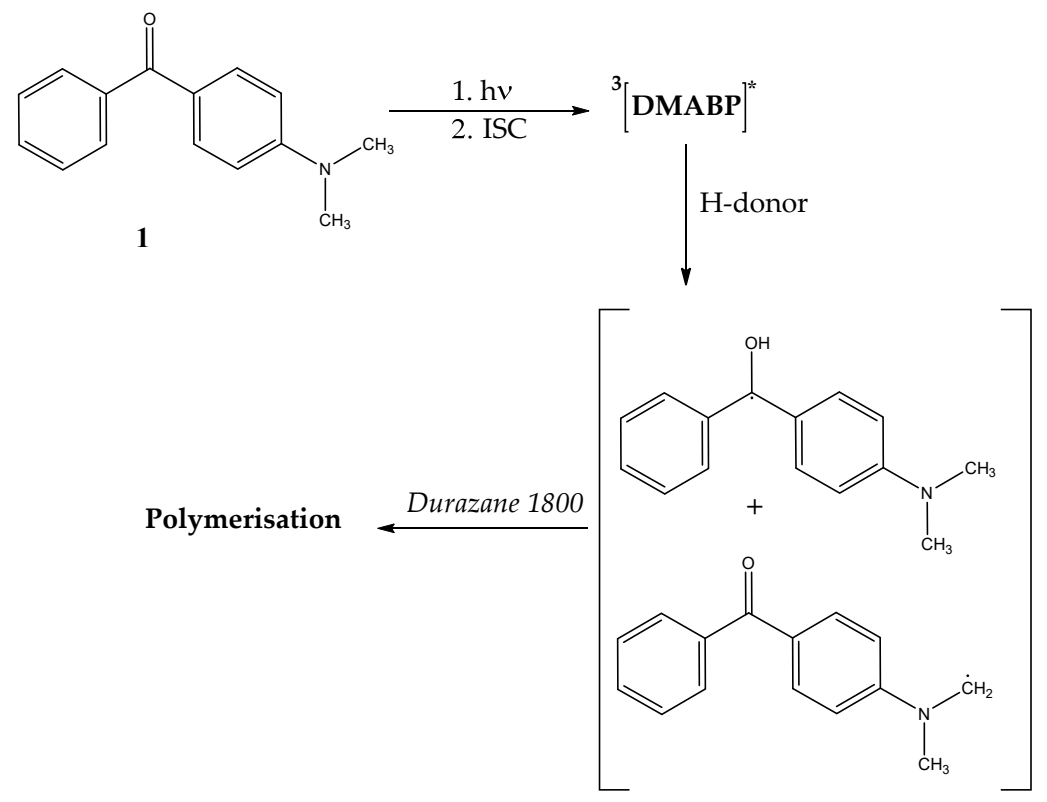

Figure 3. Schematic illustration of the initiation of DMABP upon UV light.

In inert atmosphere, Durazane 1800 can be primarily crosslinked through three different chemical bonds: $\equiv \mathrm{Si}-\mathrm{H}, \equiv \mathrm{Si}-\mathrm{NH}-\mathrm{Si} \equiv$, and $\mathrm{RCH}=\mathrm{CH}_{2}$ (vinyl group). The crosslinking reactions are shown in Figure 4. 


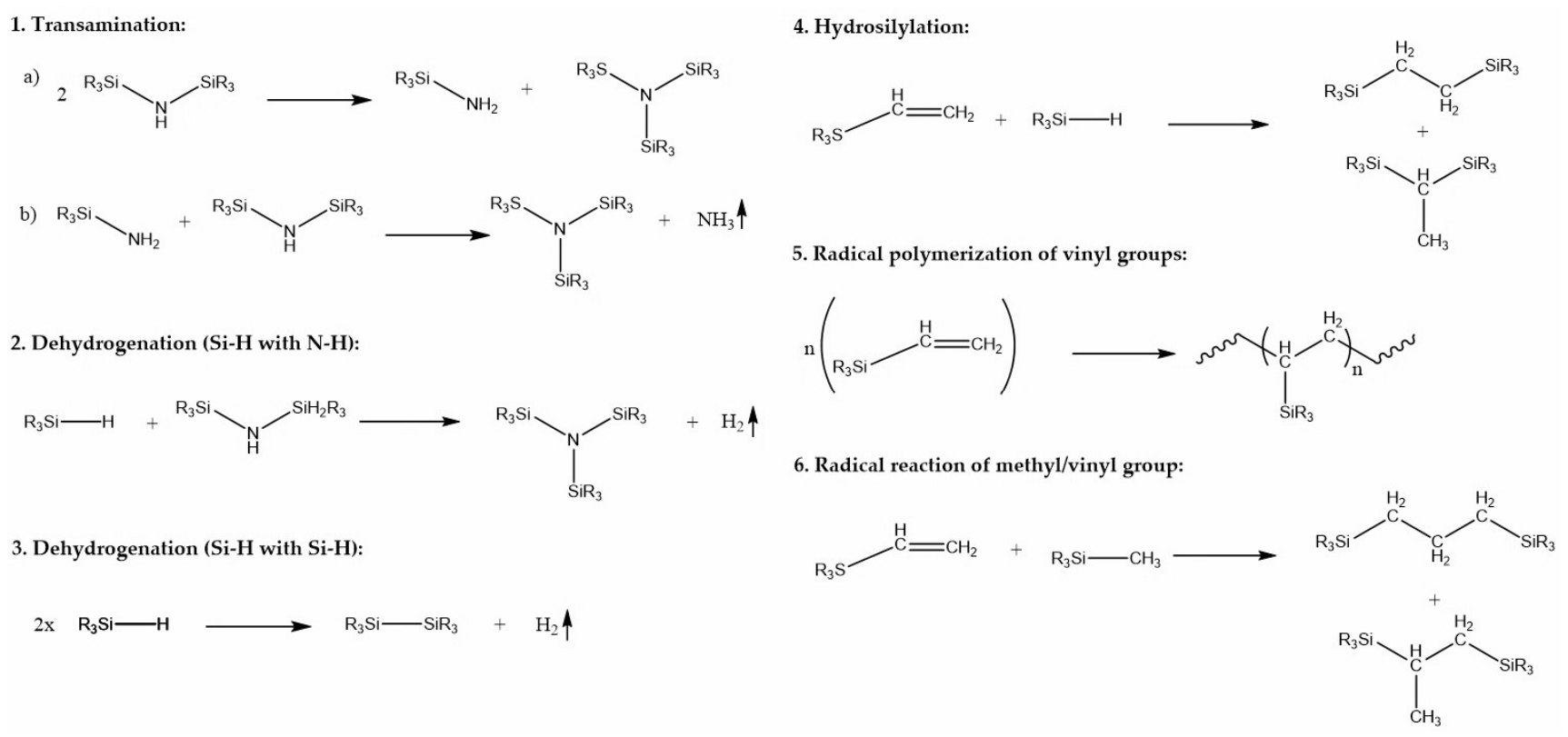

Figure 4. Several crosslinking reactions of Durazane 1800 involve $\equiv \mathrm{Si}-\mathrm{H}, \equiv \mathrm{Si}-\mathrm{NH}-\mathrm{Si} \equiv$, and $\mathrm{RCH}=\mathrm{CH} 2$ groups that can occur in inert atmosphere [9].

The main group that undergoes a crosslinking reaction is the vinyl group. It is involved in the radical vinyl polymerization and hydrosilylation of Si-vinyl and $\equiv \mathrm{Si}-\mathrm{H}$ groups. The possible radical reaction of methyl and vinyl groups, which occurs at temperatures above $200{ }^{\circ} \mathrm{C}$ [35], can be neglected in this work. Moreover, the $\equiv \mathrm{Si}-\mathrm{H}$ bond undergoes dehydrogenation reactions between two $\equiv \mathrm{Si}-\mathrm{H}$ bonds and/or between $\equiv \mathrm{Si}-\mathrm{H}$ and $\equiv \mathrm{Si}-\mathrm{NH}-\mathrm{Si} \equiv$ groups. Finally, the $\equiv \mathrm{Si}-\mathrm{NH}-\mathrm{Si} \equiv$ group can crosslink via transamination reaction $[7,9,36]$.

In ambient atmosphere, the crosslinking reactions are mostly hydrolysis and polycondensation reactions [37]; these are shown in Figure 5. Thereby, the $\equiv \mathrm{Si}-\mathrm{NH}-\mathrm{Si} \equiv$ group reacts with a water or an oxygen molecule under formation of silanol groups, which subsequently polymerize to polysiloxane via polycondensation.

\section{Hydrolysis and polycondensation reaction:}

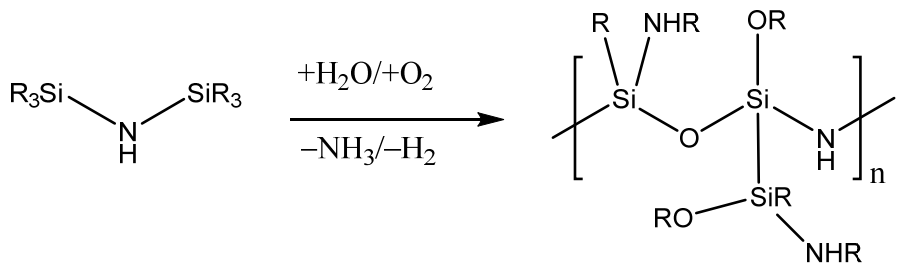

Figure 5. Hydrolysis and polycondensation reaction of Durazane 1800 in ambient atmosphere.

\section{Results and Discussion}

\subsection{UV-VIS Spectroscopy}

The UV-VIS spectra of the photoinitiators were recorded in order to distinguish at which absorption maximum the PIs absorb UV-light for starting the polymerization reaction of polysilazane. Figure 6 illustrates the absorbance spectra of the photoinitiators and Table 2 summarizes the absorption maxima. 


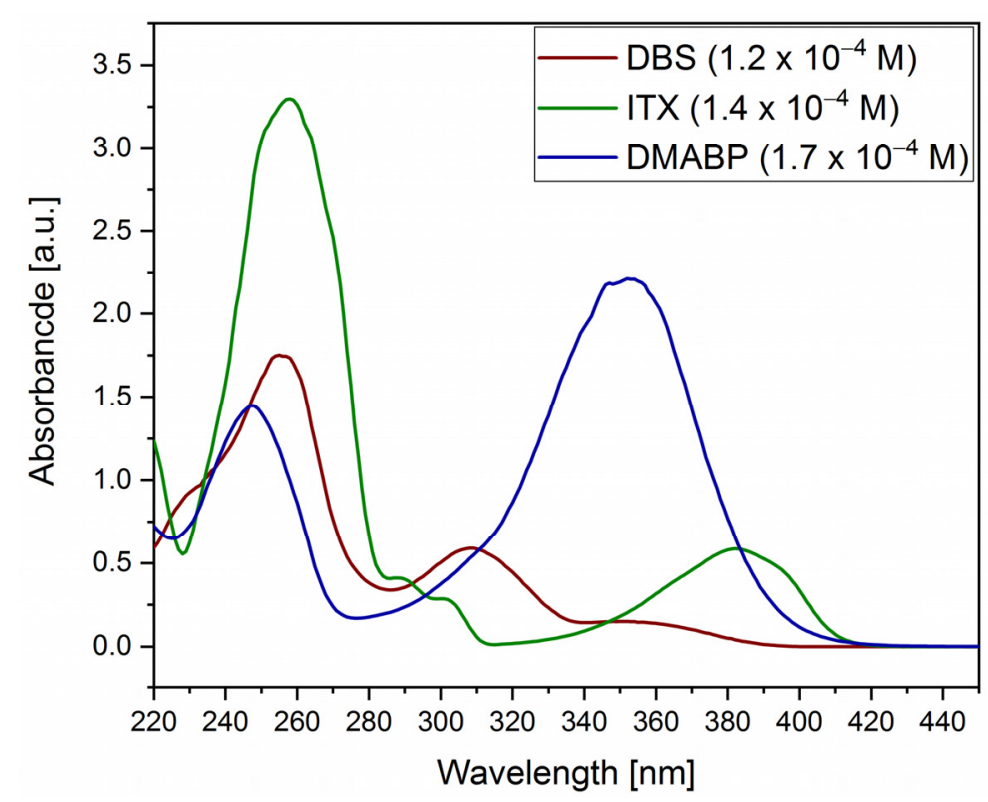

Figure 6. Absorption spectra of the photoinitiators in 2-propanol solution.

Table 2. Summary of the absorption maxima of the photoinitators classified according to the different UV ranges.

\begin{tabular}{cccc}
\hline & UV-C & UV-B & UV-A \\
\hline Photoinitiator & $\begin{array}{c}\text { Absorption } \\
\text { Maximum } \lambda_{\text {max }}\end{array}$ & $\begin{array}{c}\text { Absorption } \\
\text { Maximum } \lambda_{\text {max }}\end{array}$ & $\begin{array}{c}\text { Absorption } \\
\text { Maximum } \lambda_{\text {max }}\end{array}$ \\
\cline { 2 - 4 } & {$[\mathbf{n m}]$} & {$[\mathbf{n m}]$} & {$[\mathbf{n m}]$} \\
\hline DBS & 255 & 307 & 352 \\
ITX & 258 & $290 ; 301$ & 382 \\
DMABP & 248 & - & 351 \\
\hline
\end{tabular}

The photoinitiator shows different absorption maxima, starting with ITX (Figure 6, green curve), which has two major absorption maxima at $258 \mathrm{~nm}$ and $382 \mathrm{~nm}$ in the UV-C and UV-A region, respectively, combined with two small shoulders between 290 and 301 $\mathrm{nm}$ in the UV-B region. The photoinitiator ITX is a derivate of benzophenone with a modification of a sulfur atom bridge between the two phenyl groups. Owing to the sulfur atom, the UV absorption spectra are redshifted compared with benzophenone [34].

As ITX, DBS (Figure 6) absorbs in the UV-region, showing the major maximum at $255 \mathrm{~nm}$, followed by an absorption maximum at $307 \mathrm{~nm}$ and a small broad shoulder between 340 and $380 \mathrm{~nm}$. Lastly, DMABP (Figure 6) is the only PI, which does not absorb in the UV-B region, showing its major absorption maximum in the UV-A region at $351 \mathrm{~nm}$ and the smaller absorption maximum at $248 \mathrm{~nm}$. In this work, the UV-A region is of interest, as the employed light source has a light emitting diode for the emission of homogenous irradiation at a wavelength of 385 or $405 \mathrm{~nm}$.

\subsection{FTIR Analysis}

FTIR analysis was carried out before and after the UV curing to analyze the crosslinking behavior and to characterize the chemical structure of the samples. The relative degree of conversion was calculated for the reactive bonds $(\equiv \mathrm{Si}-\mathrm{H}, \equiv \mathrm{Si}-\mathrm{NH}-\mathrm{Si} \equiv$, and the vinyl group), which are detected by FTIR spectroscopy. The non-reactive group $\equiv \mathrm{Si}-\mathrm{CH}_{3}$, with a sharp band at about $1256 \mathrm{~cm}^{-1}$, is a common characteristic of all FTIR spectra of Durazane 1800 , as it was synthesized through an ammonolysis reaction of dichloromethylsilanes $\left(\mathrm{RCH}_{3} \mathrm{SiCl}_{2}, \mathrm{R}=\mathrm{H}, \mathrm{CH}_{3}\right.$, or $\left.\mathrm{CH}=\mathrm{CH}_{2}\right)$ [7]. The $\equiv \mathrm{Si}-\mathrm{CH}_{3}$ group is used as a reference for all calculations of the crosslinking process. 
The FTIR spectra of DMABP01-DMABP08 are presented in Figure 7a-d. The uncured samples (black curves) show the characteristic bands of pure Durazane 1800, which are mainly summarized in Table A1. The absorption bands below $1000 \mathrm{~cm}^{-1}$ relate to the stretching and deformation vibrations of $\mathrm{Si}-\mathrm{C}, \mathrm{Si}-\mathrm{N}, \mathrm{C}-\mathrm{C}$, and $\mathrm{C}-\mathrm{H}$ bonds, which, however are overlapping and consequently cannot be accurately assigned.
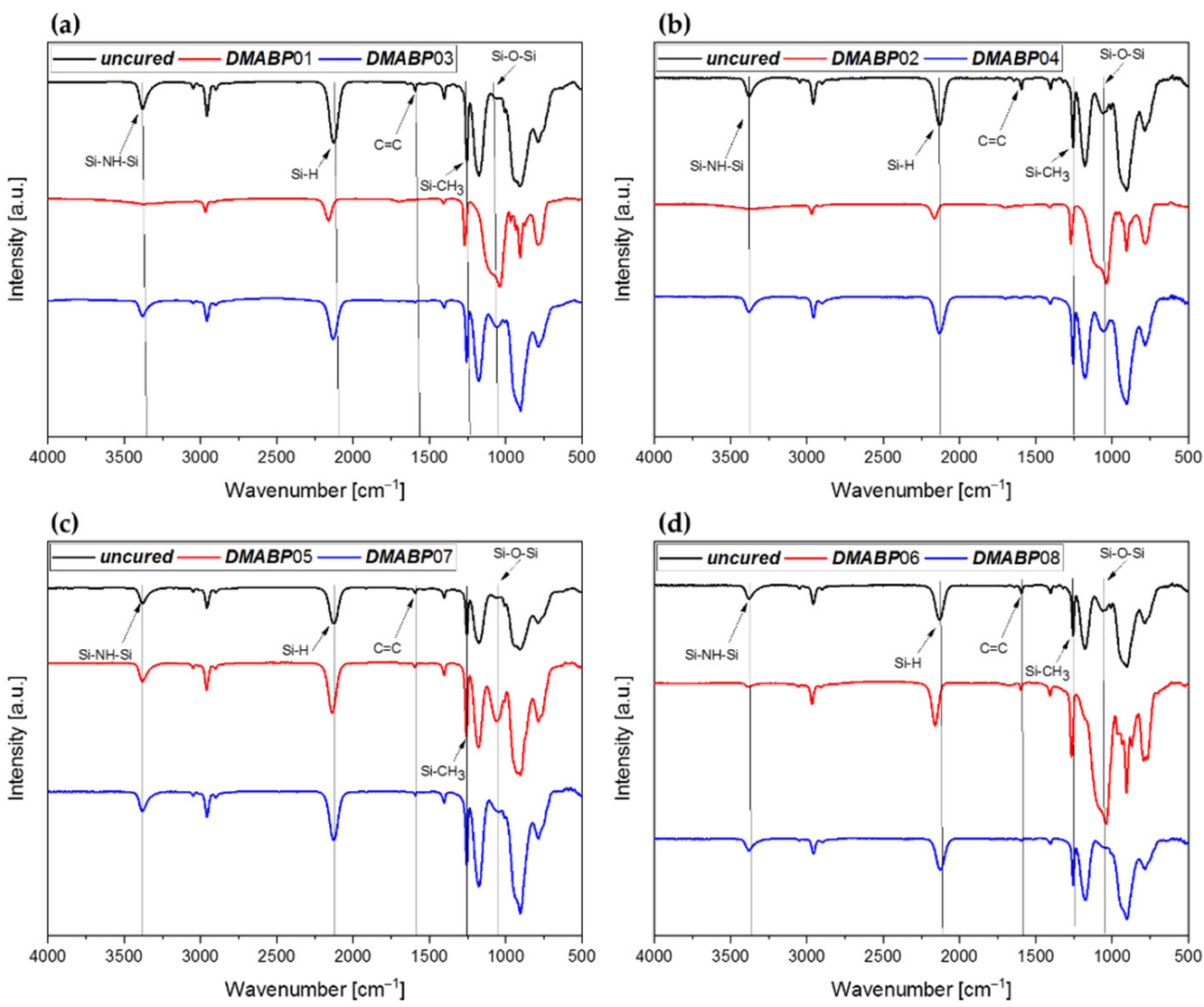

Figure 7. FITR spectra of the uncured and cured Durazane 1800 sample mixed with DMABP as photoinitiator. The red curves are samples cured in ambient atmosphere and the blue curves in nitrogen atmosphere. Black curves belong to the uncured samples. (a) DMABP01 and DMABP03, (b) DMABP02 and DMABP04 cured by a UV lamp $(\lambda=385 \mathrm{~nm})$. (c) DMABP05 and DMABP07, (d) DMABP06 and DMABP08 cured by a UV lamp $(\lambda=405 \mathrm{~nm})$.

In this work, the focus of attention lies on the reactive chemical bonds in the case of the uncured samples, including the vinyl group as well as the $\equiv \mathrm{Si}-\mathrm{H}$ and $\equiv \mathrm{Si}-\mathrm{NH}-\mathrm{Si} \equiv$ bond (Table 3). The absorption band at $1050 \mathrm{~cm}^{-1}$, corresponding to the $\equiv \mathrm{Si}-\mathrm{O}-\mathrm{Si} \equiv$, is only visible in Figure $7 \mathrm{~b}$, d. A possible reason for the $\equiv \mathrm{Si}-\mathrm{O}-\mathrm{Si} \equiv$ band in the uncured samples is the higher amount of photoinitiator, which might induce a slight silanol reaction during preparation in ambient atmosphere. After using Durazane 1800, the bottle is flooded with nitrogen to prevent oxygen contamination. Nevertheless, the oxygen cannot be completely avoided, as in the case of inert atmosphere.

The FTIR spectra of sample DMABP03/04 and DMABP07/08 were recorded after UV curing by a LED source $(\lambda=385$ and $405 \mathrm{~nm})$ in nitrogen atmosphere. In these conditions, the spectra of the cured samples reveal similar features as the uncured reference samples, except for the decrease of the deformation vibrations of the vinyl group (Figure 7, blue curves) at the wavenumber of $1596 \mathrm{~cm}^{-1}$. This indicates that the conversion of the vinyl group via radical polymerization is mainly responsible for the curing of Durazane 1800. The observation is supported by the calculation of the degree of conversion (DC, vinyl group) shown in Figure 8 and Table A1, which is three times as high as the DC of the $\mathrm{Si}-\mathrm{H}$ and $\mathrm{N}-\mathrm{H}$ bonds. The vinyl groups of samples DMABP03/04 convert almost completely 
(DC $=89 \%)$ using the LED source $(\lambda=385 \mathrm{~nm})$ compared with the samples DMABP07/08. A reason for this occurence might be the absorption maximum of DMABP, which is at 351 $\mathrm{nm}$ (Table 2), being closer to $385 \mathrm{~nm}$ than to $405 \mathrm{~nm}$. The DC (Si-H and N-H, Figure 8) of $D M A B P 03 / 04$ is half as high as that of $D M A B P 01 / 02$, owing to the absence of oxygen during the crosslinking process and, accordingly, little to no poly-condensation reactions of the $\mathrm{Si}-\mathrm{H}$ and $\mathrm{N}-\mathrm{H}$ groups occurred in inert atmosphere. The conversion of these bonds in inert atmosphere is based on transamination $(\mathrm{N}-\mathrm{H}$ bond) and dehydrogenation $(\mathrm{Si}-\mathrm{H})$ reactions (see Figure 4). By comparing the spectra of DMABP03/04 (blue curves) with $D M A B P 01 / 02$ (red curves), the samples cured in an inert atmosphere exhibit a minor absorption band of $\equiv \mathrm{Si}-\mathrm{O}-\mathrm{Si} \equiv$ between 1080 and $1040 \mathrm{~cm}^{-1}$, which could be completely avoided when operating in a glovebox. Moreover, the photoinitiatior DMABP is resistant against oxygen inhibition, as the aminoalkyl radical can form a peroxide radical by reacting with oxygen. In turn the peroxide radical generates another aminoalkyl radical by hydrogen abstraction [34]. This property of DMABP can be very useful when operating with material suffering from oxygen inhibition. Hence, it can be concluded that successful curing of Durazane 1800 took place using a low energetic LED source within minutes.

Table 3. Overview of important FTIR stretching and deformation vibrations in Durazane 1800 [38].

\begin{tabular}{ccc}
\hline Chemical Bonds & $\begin{array}{c}\text { Stretching Vibrations } \\
{\left[\mathbf{c m}^{-\mathbf{1}}\right]}\end{array}$ & $\begin{array}{c}\text { Deformation Vibrations } \\
{\left[\mathbf{c m}^{-\mathbf{1}}\right]}\end{array}$ \\
\hline$\equiv \mathrm{Si}-\mathrm{NH}-\mathrm{Si} \equiv$ & 3382 & 1176 \\
$\mathrm{C}=\mathrm{C}$ double bond in vinyl group & & $1596 ; 1400$ \\
$\equiv \mathrm{Si}-\mathrm{CH}_{3}$ & $1180-1120$ & 1257 \\
$\equiv \mathrm{Si}-\mathrm{CH}_{2}-\mathrm{CH}_{2}-\mathrm{Si} \equiv$ & $1080-1040$ & \\
$\equiv \mathrm{Si}-\mathrm{O}-\mathrm{Si} \equiv$ & & \\
\hline
\end{tabular}

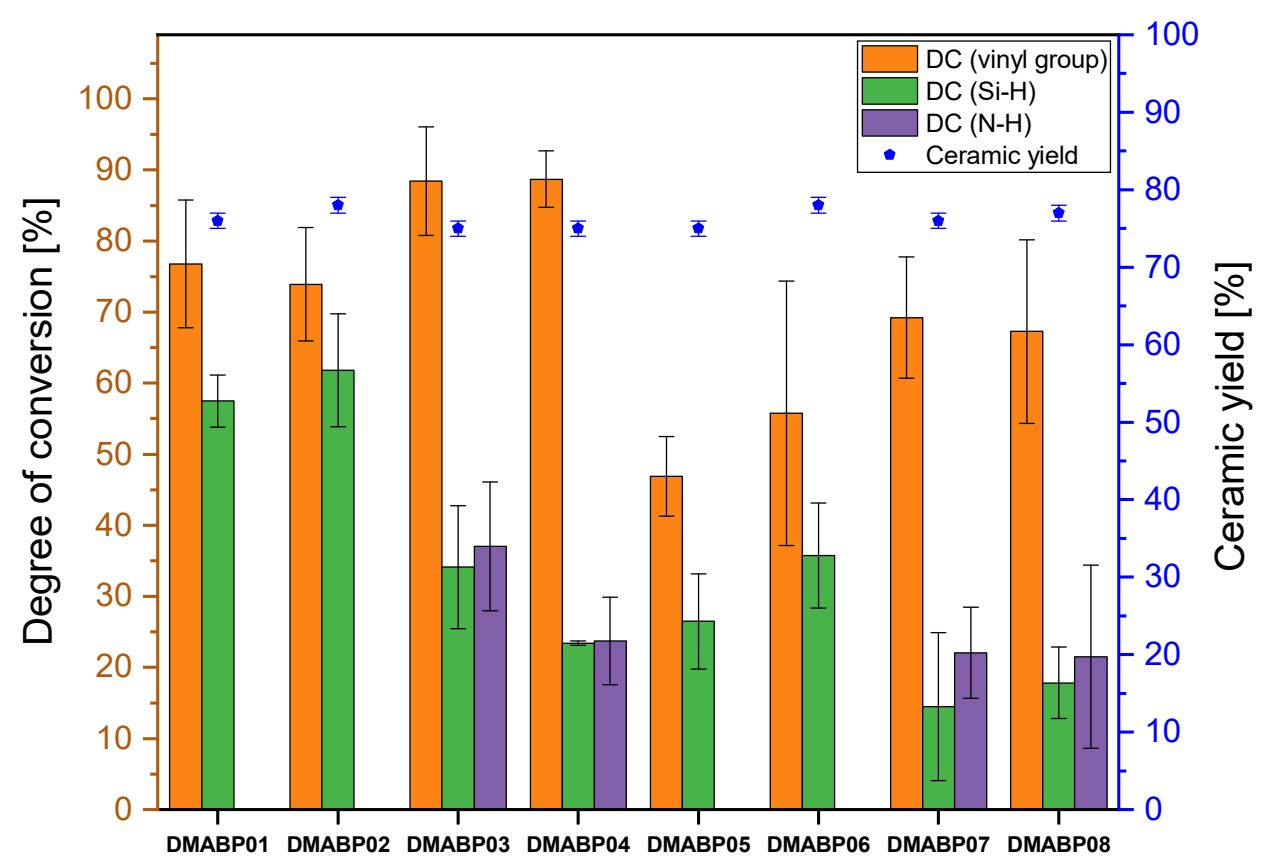

Figure 8. Degree of conversion (DC) of the reactive vinyl group as well as $\mathrm{Si}-\mathrm{H}$ and $\mathrm{N}-\mathrm{H}$ bonds calculated from the FTIR spectra of the samples DMABP01-08. The ceramic yield was obtained by thermogravimetric analysis (TGA) measurement at $1200^{\circ} \mathrm{C}$.

The FTIR spectra of $D M A B P 01 / 02$ and $D M A B P 05 / 06$ were measured after UV curing by an LED source $(\lambda=385$ and $405 \mathrm{~nm})$, respectively, in ambient atmosphere. For all samples cured in ambient atmosphere, the DC of the $\equiv \mathrm{Si}-\mathrm{NH}-\mathrm{Si} \equiv$ group was neglected, because the peak could not be distinguished properly owing to the peak broadening caused 
by water. The intensities of the bands assigned to the stretching of the $\mathrm{C}-\mathrm{H}$ bonds of the vinyl group (at $3050 \mathrm{~cm}^{-1}$ ) as well as of the $\mathrm{C}=\mathrm{C}$ double bonds at $1596 \mathrm{~cm}^{-1}$ disappeared for the samples DMABP01/02 and decreased for the samples DMABP05/06. Besides, the absorption band of the $\equiv \mathrm{Si}-\mathrm{H}$ bond decreased for all these samples. This observation indicates a hydrosilylation reaction (Figure $4,(4))$ of the $\equiv \mathrm{Si}-\mathrm{H}$ group with the vinyl group and radical polymerization of the vinyl group (Figure 4, (5)). The disappearance of the vinyl group of the samples DMABP01/02 may be due to the absorption maximum of the photoinitiator around $355 \mathrm{~nm}$ (Figure 6 and Table 2), thus corresponding more closely to the wavelength at $385 \mathrm{~nm}$ than to the $405 \mathrm{~nm}$ UV-lamp. This result is confirmed by the DC of the vinyl group, which is higher for DMABP01/02 than for DMABP05. However, it is in the same order of magnitude when comparing the samples DMABP01/02 and DMABP06, considering the measurement inaccuracy.

Moreover, the spectra of $D M A B P 01, D M A B P 02$, and DMAPB06 (Figure 7a, Figure 7b, and Figure $7 \mathrm{~d}$, respectively, red curves) show the absorption band of $\equiv \mathrm{Si}-\mathrm{O}-\mathrm{Si} \equiv$. The reason is the hydrolysis of the $\equiv \mathrm{Si}-\mathrm{NH}-\mathrm{Si} \equiv$ group resulting in a silanol group $(\equiv \mathrm{Si}-\mathrm{OH})$ and ammonia, followed by a polycondensation reaction (Figure 5). This crosslinking reaction is confirmed by nearly complete disappearance of both the stretching and deformation vibrations of the $\mathrm{Si}-\mathrm{NH}$ band. The absorption band of the $\mathrm{Si}-\mathrm{O}-\mathrm{Si}$ of sample $D M A B P 05$ (Figure 7c) is not as strong in the case of DMABP01/02 and DMABP06, despite being polymerized similarly. In addition, neither the stretching nor the deformation vibrations of the $\equiv \mathrm{Si}-\mathrm{NH}-\mathrm{Si} \equiv$ group fully disappeared in this sample, despite curing in ambient atmosphere. One reason for this observation could be the low concentration of the photoinitiator compared with sample DMABP06, and another reason could be the lower energetic irradiation of the LED source $(\lambda=405 \mathrm{~nm})$. Moreover, the DC of the $\mathrm{Si}-\mathrm{H}$ bond of samples $D M A B P 01 / 02$ is higher than that of samples DMABP05/06, implying more silanol and polycondensation reactions of the bonds $\equiv \mathrm{Si}-\mathrm{H}$ and $\mathrm{N}-\mathrm{H}$ occurred at the wavelength $385 \mathrm{~nm}$ than at $405 \mathrm{~nm}$. The hydrolysis of Si-H bond can be catalyzed by the ammonia formed from hydrolysis reactions of the $\equiv \mathrm{Si}-\mathrm{NH}-\mathrm{Si} \equiv$ group [39]. Especially in sample $D M A B P 05$, the $\mathrm{DC}(\equiv \mathrm{Si}-\mathrm{H})$ is much lower than in sample $D M A B P 06$, indicating less hydrolysis and polycondensation reactions, as proven in the spectra (Figure 7c) by the unreacted absorption peaks of the $\equiv \mathrm{Si}-\mathrm{NH}-\mathrm{Si} \equiv$ bond. This result shows that Durazane 1800 does not completely hydrolyse during curing, even in these conditions. Thermally, this could not be observed, as more energy is given into the system. However, this absorption band occurs for all samples cured in ambient atmosphere owing to the sensitivity of Durazane 1800 to moisture $[37,40,41]$.

Compared with DMABP and ITX, the samples mixed with DBS could not be cured by near visible light LED $(\lambda=405 \mathrm{~nm}$ ), owing to its absorbance maxima (Figure 6) and the structure of DBS (Figure 2). As it only consists of phenyl-groups without heteroatom like sulfur or the amino alkyl group, the absorbance spectrum is not red-shifted. The photoinitiator concentration does not affect the $\mathrm{DC}$ (vinyl group, $\equiv \mathrm{Si}-\mathrm{H}$, and $\mathrm{N}-\mathrm{H}$ ) for all samples. For the coating application, it is advantageous to use a higher amount of photoinitiator if thinner layers are desired [34].

The samples DBS01-04 were cured by the LED source $(\lambda=385 \mathrm{~nm})$ in ambient and nitrogen atmosphere followed by the measurement of the FTIR spectra, which are illustrated in Figure $9 a, b$.

Samples DBS03/04 were cured in nitrogen atmosphere and, as shown in Figure 9, an $\mathrm{Si}-\mathrm{O}-\mathrm{Si}$ absorption band $\left(\sim 1060 \mathrm{~cm}^{-1}\right)$ was formed, implying that the samples were partially hydrolyzed. As shown in Figure 9b, the spectra of the uncured mixture already show an Si-O-Si band, indicating the sensitivity of the Durazane 1800/DBS system to oxygen. Nevertheless, the crosslinking behavior is supported by radical polymerization of the vinyl group (DC up to $85 \%$ ), as the absorbance band of the vinyl group has decreased. Compared with DMABP03/04, the DC (N-H) is higher for DBS03/04 because the $\mathrm{N}-\mathrm{H}$ group works as a co-initiator in the initiation reaction of DBS. Additionally, transamination and dehydrogenation reactions with the $\mathrm{Si}-\mathrm{H}$ bond (DC 40\%) may have occurred. 
(a)

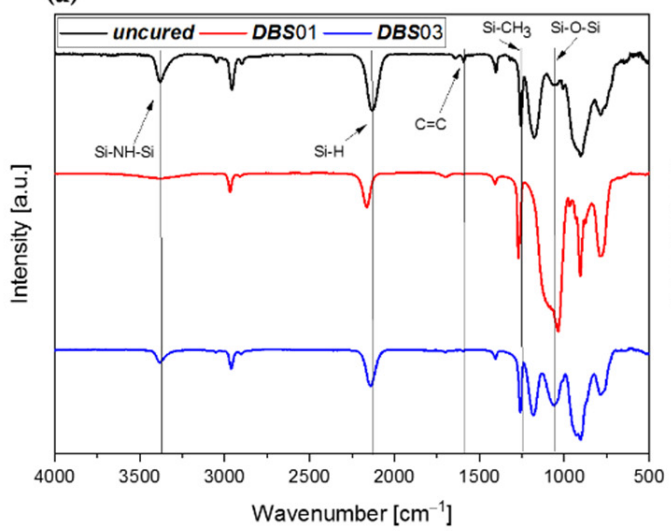

(b)

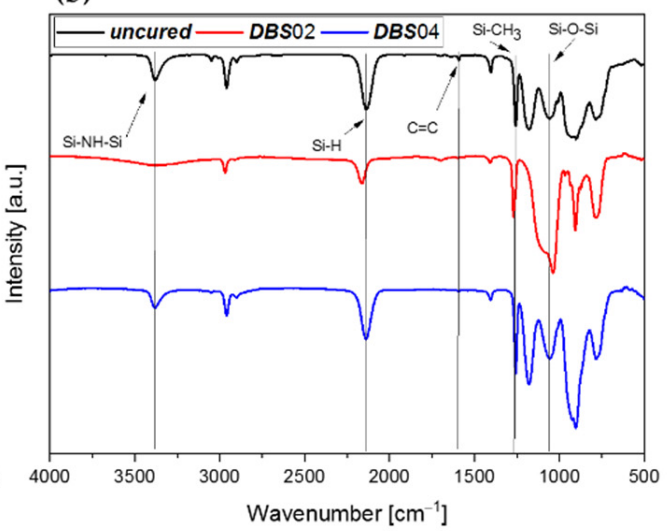

Figure 9. FTIR spectra of the uncured and cured Durazane 1800 sample mixed with DBS as photoinitiator. The red curves were cured in ambient and the blue curves in nitrogen atmosphere. Black curves belong to the uncured sample. (a) DBS01 and DBS03, (b) DBS02 and DBS04 cured by the LED source $(\lambda=385 \mathrm{~nm})$.

Similar to $D M A B P 01 / 02$, samples $D B S 01 / 02$ cured in ambient atmosphere (red curves) also undergo hydrolysis and polycondensation reactions illustrated in Figure 9 by the formation of an Si-O-Si absorption band. Moreover, the vinyl group is converted as the absorption band decreases and the resulting DC (vinyl group) accounts for approximately $75 \%$ (Figure 10). The vinyl group possibly reacts with the Si-H bond (DC 60\%) by hydrosilylation reaction, forming an $\mathrm{Si}-\mathrm{C}$ linkage, or via radical polymerization.

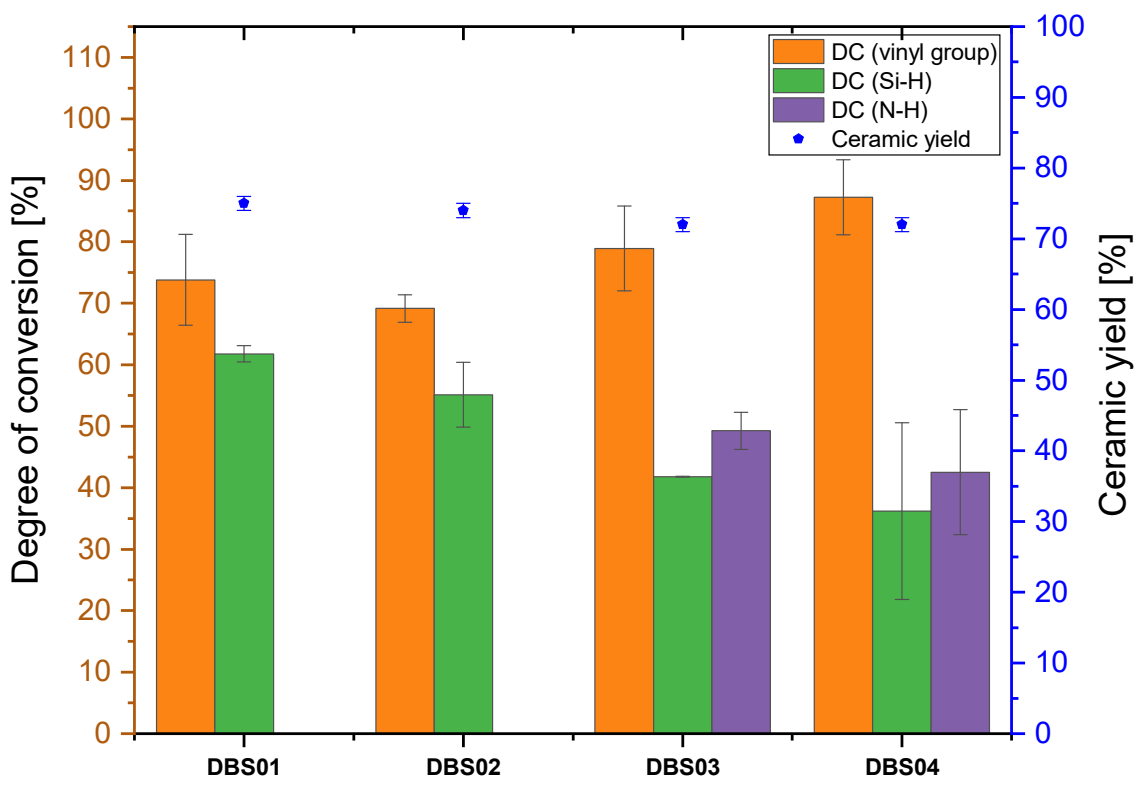

Figure 10. Degree of conversion of the reactive vinyl group as well as $\equiv \mathrm{Si}-\mathrm{H}$ and $\mathrm{N}-\mathrm{H}$ bonds calculated from the FTIR spectra of samples DBS01-04. The ceramic yield was obtained by TGA measurement at $1200^{\circ} \mathrm{C}$.

By mixing Durazane 1800 with the photoinitiator ITX, both LED sources could be used for curing the mixtures owing to the red shifting of ITX generated by the sulfur atom. The FTIR spectra and the resulting degree of conversion of the reactive bonds are shown in Figures 11 and 12, respectively. 


\section{(a)}

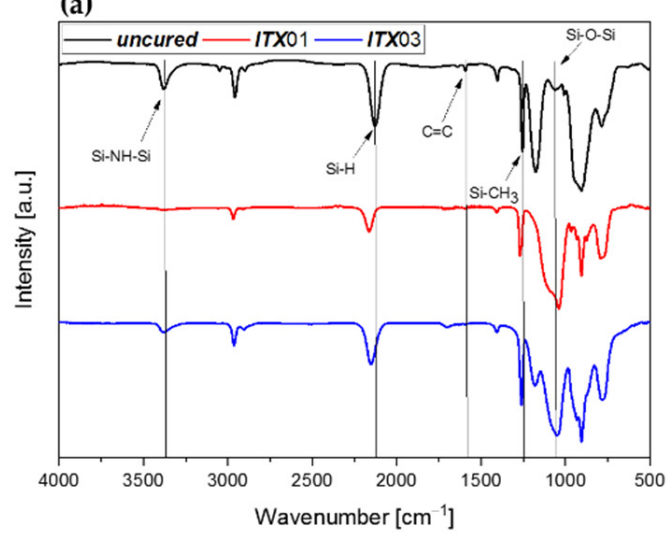

(c)

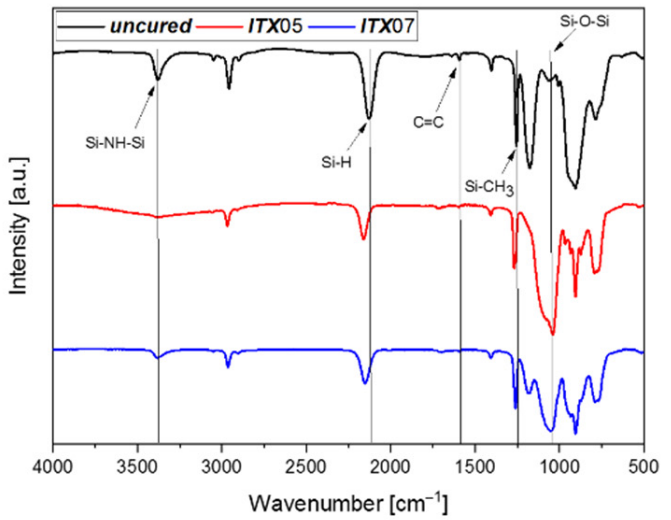

(b)

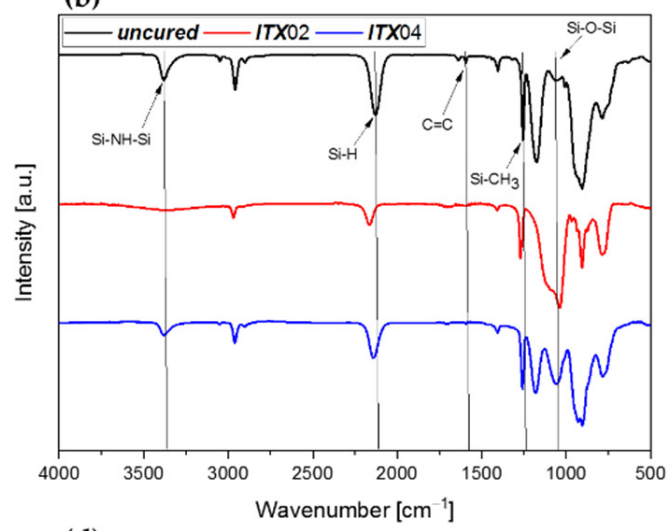

(d)

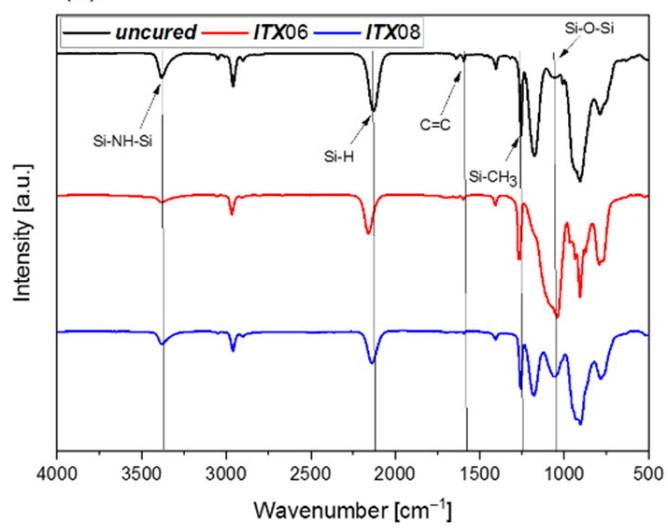

Figure 11. FTIR spectra of the uncured and cured Durazane 1800 sample mixed with DMABP as photoinitiator. The red curves were cured in ambient atmosphere and the blue curves in nitrogen atmosphere. Black curves belong to the uncured sample. (a) ITX01 and ITX03, (b) ITX02 and ITX04 cured by the LED source $(\lambda=385 \mathrm{~nm}$ ). (c) ITX05 and ITX07, (d) ITX06 and ITX 08 cured by the LED source $(\lambda=405 \mathrm{~nm})$.

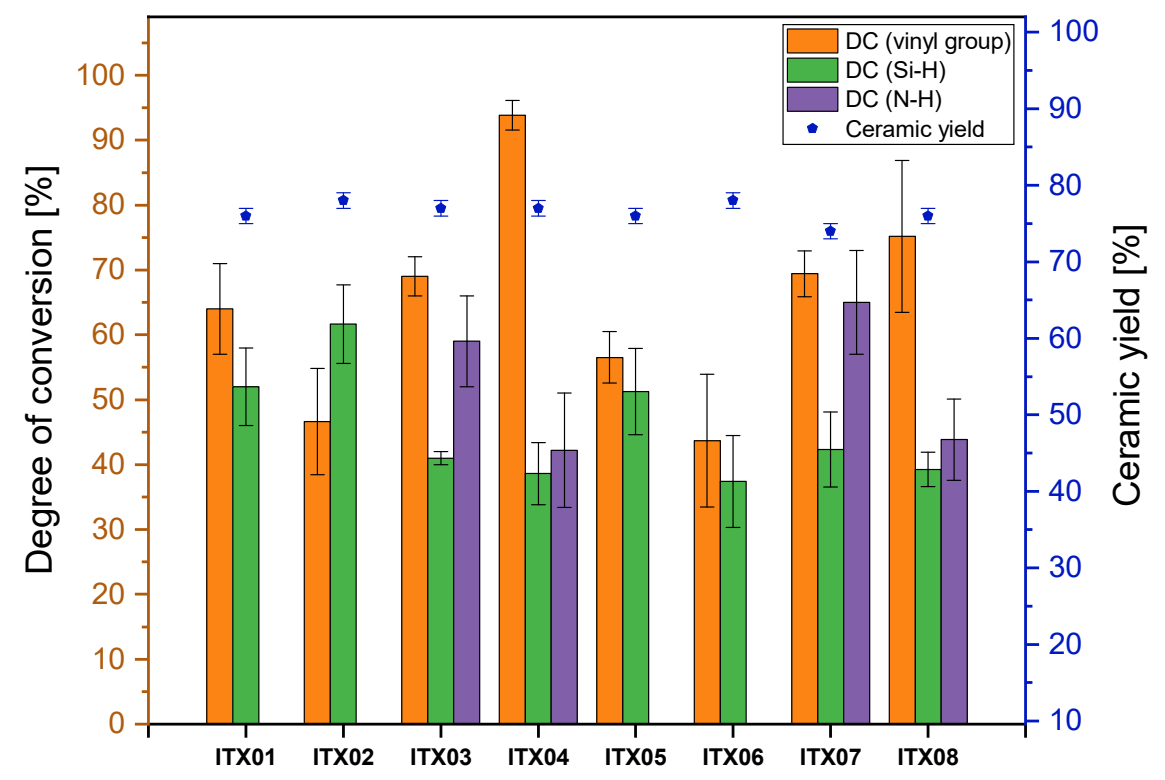

Figure 12. Degree of conversion of the reactive vinyl group as well as $\equiv \mathrm{Si}-\mathrm{H}$ and $\mathrm{N}-\mathrm{H}$ bonds calculated from the FTIR spectra of the samples ITX01-08. The DC $(\mathrm{N}-\mathrm{H})$ of the samples cured in nitrogen atmosphere. The ceramic yield was obtained by TGA measurement at $1200{ }^{\circ} \mathrm{C}$. 
The initial aspect that is noticeable when analyzing the spectra of the samples (ITX03/04 and ITX07/08) polymerized in nitrogen atmosphere is the formation of the $\equiv \mathrm{Si}-\mathrm{O}-\mathrm{Si} \equiv$ bond in spite of the inert atmosphere. The $\equiv \mathrm{Si}-\mathrm{O}-\mathrm{Si} \equiv$ bond is more evident for samples ITX03/07 than for ITX04/08. This result is represented by the corresponding DC (N-H), which is larger for ITX03/07 than for ITX04/08. One reason for this occurence might be the lower photoinitiator concentration, leading to a slower, nevertheless more homogenous, initiation of the photoinitiator, and thus to a slower gelation. However, as the N-H group co-initiates the photoinitiator, the conversion is higher with the lower concentrations of the initiator than at higher concentrations, because more radical centers could be activated owing to the slower reaction. The DC (vinyl group) of ITX04 is higher than ITX03, which is desirable, as the $\mathrm{Si}-\mathrm{C}$ linkage observed by hydrosilylation reaction is stable at elevated temperatures.

As can be seen in the spectra (Figure 11), the samples (ITX01/02, ITX05/06) cured in ambient atmosphere were hydrolyzed similarly to the aforementioned mixtures of Durazane 1800 with DBS and DMABP. The calculated DC of the vinyl and the Si-H bonds are in the same order of magnitude for ITX01/02 and ITX05/06 and are to be attributed to hydrosilylation reactions and radical polymerization of the vinyl group.

The FTIR spectra of the samples pyrolyzed at $950{ }^{\circ} \mathrm{C}$ are shown in Figure 13 of the samples cured in nitrogen and ambient atmosphere. The ceramization process was completed as no absorption of $\mathrm{Si}-\mathrm{H}$ or $\mathrm{C}-\mathrm{H}$ bonds is present. A broad absorption band is visible between 1100 and $680 \mathrm{~cm}^{-1}$ attributed to $\mathrm{Si}-\mathrm{C}, \mathrm{Si}-\mathrm{N}-\mathrm{Si}$, and $\mathrm{Si}-\mathrm{O}-\mathrm{Si}$ bonds. As previously mentioned, the presence of oxygen refers to the sensitivity of Durazane 1800 to moisture. Even if the crosslinking and pyrolysis processes took place in nitrogen atmosphere, the mixtures were prepared in ambient atmosphere. As expected, the $\mathrm{Si}-\mathrm{O}-\mathrm{Si}$ bond is more evident for DBS04 and ITX04 compared with DMABP04, as the spectra of the cured samples already showed the $\mathrm{Si}-\mathrm{O}-\mathrm{Si}$ absorption band.

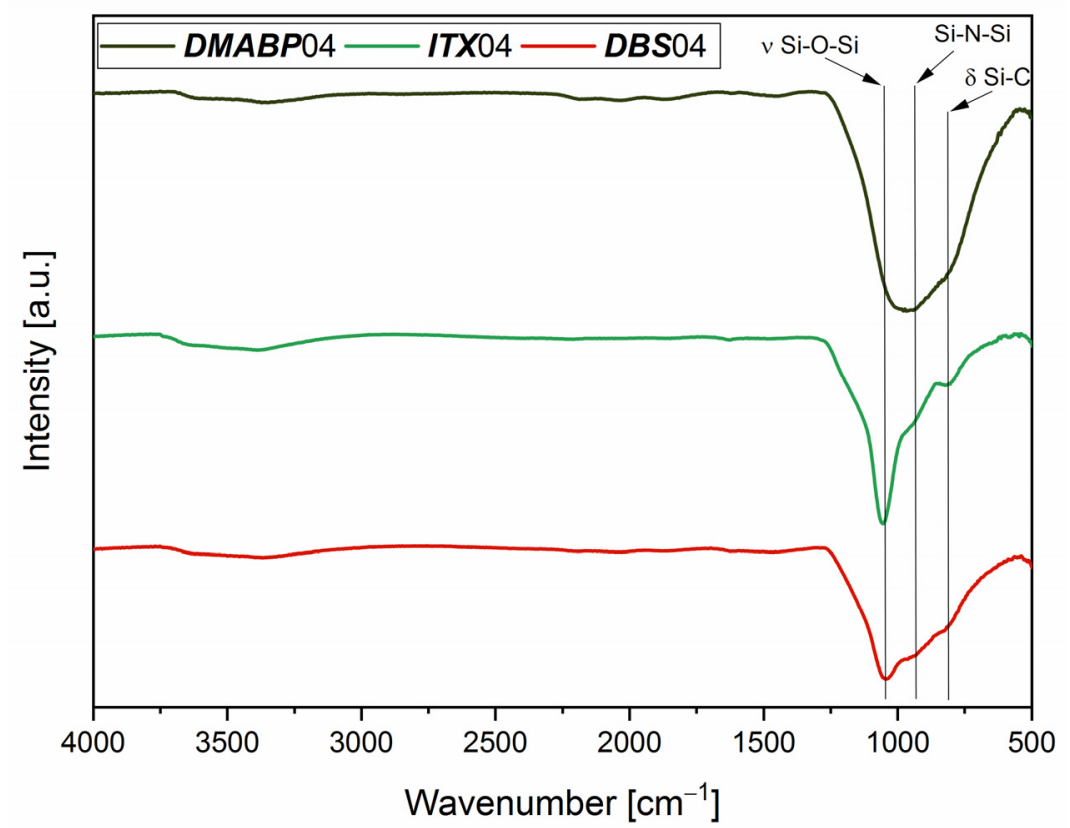

Figure 13. FTIR spectra of amorphous DMABP04, ITX04, and DBS04 pyrolyzed in nitrogen at $950{ }^{\circ} \mathrm{C}$.

\subsection{Thermogravimetric Analysis and Ceramic Yields}

Thermogravimetric analysis was conducted under nitrogen flow with $10{ }^{\circ} \mathrm{C} / \mathrm{min}$ to study the decomposition of the preceramic polymer and to measure the ceramic yield of the sample. The ceramic yield of all samples was taken of the residual mass at $1200{ }^{\circ} \mathrm{C}$ and is plotted for each mixture in Figures 8, 10 and 12. The thermograms measured in 
nitrogen atmosphere are shown in Figures A1 and A2 for the samples cured by the LED source $(\lambda=385$ and $405 \mathrm{~nm})$, respectively. Thermal behavior in nitrogen atmosphere will be explained using the sample DMABP04 as an exemplary sample in comparison with uncured Durazana 1800, as the cured samples exhibit very similar thermal behavior. Sample $D M A B P 04$ was cured by LED source $(\lambda=385 \mathrm{~nm})$. The thermograms of uncured Durazane 1800 measured in ambient and nitrogen atmosphere and of DMABP04 are presented in Figure 14.

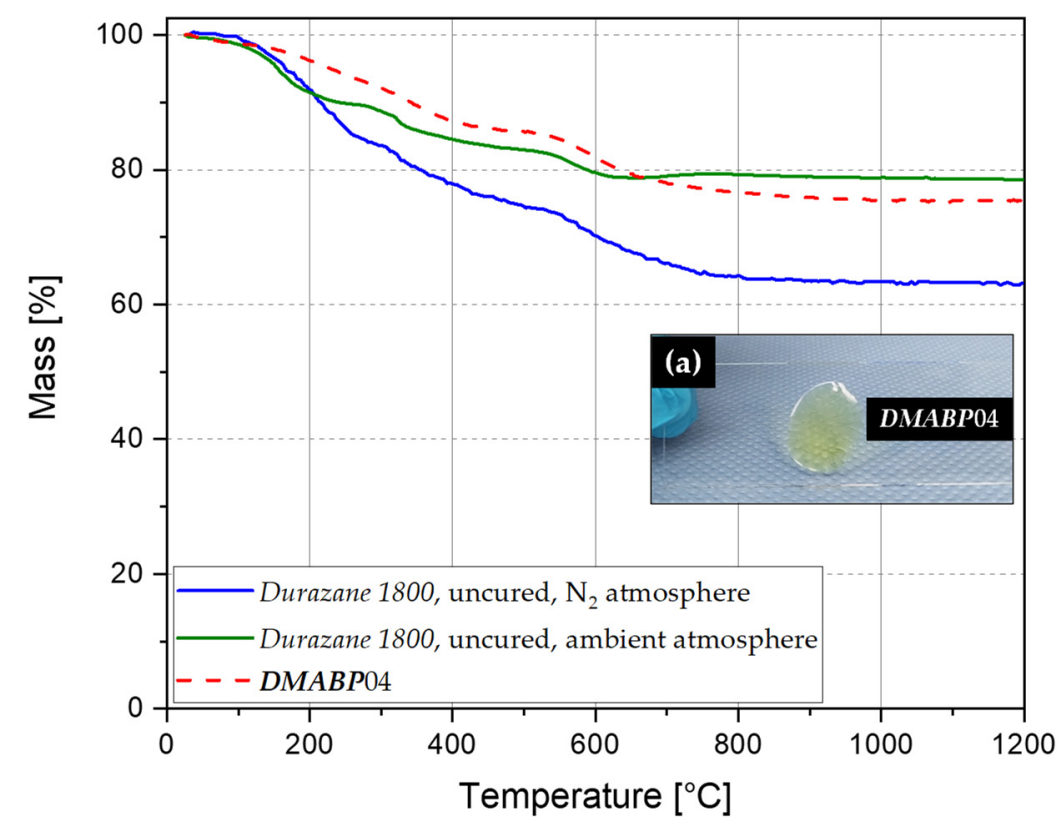

Figure 14. Thermograms of uncured Durazane 1800 measured in ambient and nitrogen atmosphere (olive and blue curve). The thermogram of DMABP04 was measured in nitrogen atmosphere after curing by an LED source $\left(\lambda=385 \mathrm{~nm}, \mathrm{~N}_{2}\right)$. (a) Drop of DMABP04 on a slide after UV curing.

Pure and uncured Durazane 1800, which was measured both in nitrogen and ambient atmosphere, decomposes in a three-step process. The degradation starts below $100{ }^{\circ} \mathrm{C}$ with a mass loss of 16 and 10\%, respectively, because of the non-crosslinked volatile oligomers. It is worth mentioning that the first step is interrupted by a small plateau between 200 and $300{ }^{\circ} \mathrm{C}$, which is attributable to the free-radical polymerization of the vinyl groups. This plateau is missing in the UV-cured samples because the vinyl group was already radically converted. The second step begins between 300 and $530{ }^{\circ} \mathrm{C}$ and results in a mass loss of about 10 and $7 \%$, respectively, owing to dehydrogenation and transamination reactions. During the third step, which starts between 530 and $850{ }^{\circ} \mathrm{C}$, the polymer-toceramic transformation takes place as described before and results in a mass loss of 10 and $4 \%$, respectively. The ceramic yield of pure Durazane 1800, measured in nitrogen and ambient atmosphere, is 63 and $80 \%$, respectively. The main reason for the increase of ceramic yield is the incorporation of oxygen through hydrolysis and polycondensation reactions of Durazane 1800 [40,42].

The degradation of the cured samples proceeds in a two-step process. The first step starts at temperatures between 120 and $400{ }^{\circ} \mathrm{C}$. During this step, further dehydrogenation and transamination reactions occur, leading to mass loss due to volatile groups like ammonia and hydrogen. Furthermore, at temperatures higher than $100{ }^{\circ} \mathrm{C}$, the non-crosslinked volatile oligomers degrade, resulting in mass loss. On the other hand, at temperatures higher than $200{ }^{\circ} \mathrm{C}$, the residual vinyl groups undergo further radical polymerization and form a thermoset. Therefore, the curve between 200 and $400{ }^{\circ} \mathrm{C}$ is more flat than sharp. The second step starts between 500 and $750{ }^{\circ} \mathrm{C}$, resulting in a mass loss due to the organic-inorganic transformation of the thermoset into amorphous $\mathrm{SiCN}$ and $\mathrm{SiCO}$, 
depending on the curing atmosphere. The organic substituents degrade into methane and other volatile hydrocarbons, hydrogen, ammonia, and volatile silicon derivatives [12], mainly owing to rearrangements and radical reactions leading to bond breaking and new bond formation [43]. No further mass loss is observed at temperatures higher than $800{ }^{\circ} \mathrm{C}$.

In comparison with the uncured Durazane 1800 (63\% in $\mathrm{N}_{2}$ atmosphere), the ceramic yield of the samples crosslinked via LED source $(\lambda=385$ and $405 \mathrm{~nm})$ increased significantly up to the range of between 72 and $78 \%$ depending on the mixture and crosslinking atmosphere (see Appendix A, Table A1). Crosslinking of the preceramic polymers is necessary for the polymer-to-ceramic transformation, as it increases the ceramic yield by reducing the volatilization of the oligomers [44]. The high ceramic yield confirmed the high degree of conversion. In addition, it demonstrates the response of Durazane 1800 to the chosen crosslinking approach. For increasing the ceramic yield and reducing the shrinkage of the final ceramic, crosslinking is an indispensable process, as the uncured sample is at least $10 \%$ lower than the crosslinked samples in inert atmosphere.

In this work, different parameters were changed to examine the behavior of Durazane 1800. First, the influence of the polymerization atmosphere on the ceramic yield was studied. As summarized in Table A1, the ceramic yield of DBS01/02 is slightly higher than

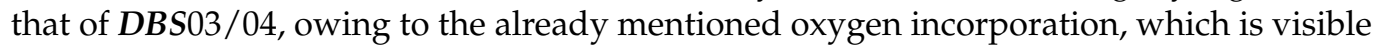
in the FTIR spectra (Figure 9). A higher ceramic yield was also observed for DMABP02 in comparison with $D M A B P 03 / 04$. For all the other samples, the polymerization atmosphere did not affect the ceramic yield. Furthermore, the photoinitiator concentration was varied for the purpose of examining the influence on the ceramic yield. The higher photoinitiator concentration does not affect the ceramic yield for most samples, except for sample ITX08, which has a higher ceramic yield than ITX07. Finally, two UV-lamps with different wavelengths were used for the photoinitiators ITX and DMABP. The change of the LED source did not influence the ceramic yield, because the ceramic yield depends on the conversion of the reactive bonds. As previously described, the mixtures presented in Table 1 were cured properly by the chosen conditions and parameter.

\section{Conclusions}

In conclusion, the present work focuses on the crosslinking behavior of polyorganosilazane (Durazane 1800), which was mixed with three different photoinitiatorsdibenzosuberone (DBS), 4-(dimethylamino)benzophenone (DMABP), and isopropylthioxanthone (ITX) — and UV irradiated by two LED sources $(\lambda=385$ and $405 \mathrm{~nm})$ in ambient and nitrogen atmosphere. It can be concluded that successful curing of Durazane 1800 was established within minutes using energy-efficient LED sources. The crosslinking behavior of the mixtures was investigated in detail by FTIR spectroscopy and the degree of conversion was calculated for the reactive bonds. The curing atmosphere has a significant impact on the crosslinking behavior of the reactive bonds and the chemical composition of the resulting ceramic. In nitrogen atmosphere, it turned out that the DMABP mixtures observed the least oxygen incorporation in comparison with the other two photoinitiators. The main reason for this occurence is the aminoalkyl radical, which can form a peroxide radical by reacting with oxygen. The peroxide radical in turn generates another aminoalkyl radical by hydrogen abstraction [34]. The resulting ceramic of the samples cured in nitrogen atmosphere is $\operatorname{SiCN}(\mathrm{O})$. The amount of oxygen depends on the curing kinetics of the photoinitiator. If the reactivity of the photoinitiator is slow, the $\mathrm{N}-\mathrm{H}$ bond will hydrolyse beforehand. Therefore, DMABP is recommended for usage as it shows the best results in terms of insensitivity to hydrolysis reactions.

The approach presented in this work can be applied to various applications, including coatings' or microelectromechanical systems' (MEMS) fabrication. Especially in the field of MEMS, the preparation of precise structures is required, so it is of great interest if a targeted curing can be carried out by means of a mask, which would not be possible with thermal curing. With the help of this approach, UV-curable inks for inkjet printing can be prepared or even 3D structures can be fabricated by stereolithography. 
In ambient atmosphere, curing of all samples is given by partial hydrolysis and polycondensation reactions owing to the sensistivity of poly(organo)silazane to water. Therefore, the resulting ceramic will be $\mathrm{SiCO}(\mathrm{N})$.

As only one spectroscopic method (FTIR) was applied in this work, it is of great importance that other methods are used to better understand and compare the presented system. FTIR spectroscopy is a fast and easy to use method. However, one disadvantage of the technique is the overlapping of the bands, which makes the method imprecise. Therefore, the use of another method such as NMR spectroscopy is indispensable, as it would identify individual bonds quite accurately.

By comparing the two used LED sources $(\lambda=385$ and $405 \mathrm{~nm})$ of the DMABP samples, it was found that the samples cured by the LED source $(\lambda=385 \mathrm{~nm})$ reached the higher degree of conversion of the reactive bonds, because this wavelength corresponds more closely to the absorption maximum of the photoinitiator. When increasing the photoinitiator concentration, a high radical concentration is available near the surface, resulting in sufficient surface cure. Accordingly, the thickness of the sample needs to be reduced to achieve complete curing as most of the light is absorbed on the surface, leading to a top to bottom amount of initiated species [45]. A lower photoinitiator concentration causes a homogeneous radical distribution, leading to good through-curing, but poor surface cure [34]. The photoinitiator concentration should be adjusted for each application depending on the film thickness desired. Moreover, the higher amount of photoinitiator results in a faster gelation owing to the higher radical concentration.

The ceramic yield was obtained by using the residual mass of the TGA and was observed in the range of 72 to $78 \%$ depending on the composition and crosslinking behavior. Hence, the curing atmosphere only influenced the ceramic yield of the DBS mixtures. In addition, the two different LED sources and the photoinitiator concentration do not affect the ceramic yield. Thus, the ceramic yield observed by the approach presented is high enough to form dense amorphous ceramics.

Author Contributions: A.Q.-H. designed and performed the experiments, collected and analyzed the data, and wrote the paper. A.Q.-H. and K.H. discussed the data. K.H. and T.H. corrected the manuscript. T.H. supervised the research. All authors have read and agreed to the published version of the manuscript.

Funding: The authors would like to thank the German Federal Ministry for Economic Affairs and Energy for funding this research within the project "IMPACT", under the grant number $0324284 \mathrm{C}$ ". The article processing charge was funded by the Baden-Wuerttemberg Ministry of Science, Research, and Art and the University of Freiburg in the funding programme Open Access Publishing.

Institutional Review Board Statement: Not applicable.

Informed Consent Statement: Not applicable.

Data Availability Statement: Not applicable.

Acknowledgments: The authors also thank the company Merck KGaA for providing the polyorganosilazane Durazane 1800. Thank you also to Christoph Pfeifer for proof-reading this manuscript.

Conflicts of Interest: Declare no conflict of interest or state. 


\section{Appendix A}

Table A1. Ceramic yield of the UV-cured samples measured from the residual mass of TGA at $1200^{\circ} \mathrm{C}$. The degree of conversion (DC) of the reactive samples calculated by the absorption bands of the FTIR spectra.

\begin{tabular}{|c|c|c|c|c|}
\hline Sample & $\begin{array}{c}\text { DC } \\
\text { (Vinyl Group) } \\
{[\%]}\end{array}$ & $\begin{aligned} & \mathrm{DC} \\
(\equiv & \mathrm{Si}-\mathrm{H}) \\
& {[\%] }\end{aligned}$ & $\begin{array}{c}\mathrm{DC} \\
(\mathrm{N}-\mathrm{H}) \\
{[\%]}\end{array}$ & $\begin{array}{c}\text { Ceramic Yield } \\
\text { at } 1200{ }^{\circ} \mathrm{C} \\
{[\%]}\end{array}$ \\
\hline Durazane 1800 uncured, $\mathrm{N}_{2}$ atmospere & - & - & - & 63 \\
\hline Durazane 1800 uncured, ambient atmospere & - & - & - & 80 \\
\hline DBS01 & $74 \pm 7$ & $62 \pm 1$ & - & 75 \\
\hline DBS02 & $69 \pm 2$ & $55 \pm 5$ & - & 74 \\
\hline DBS03 & $79 \pm 7$ & $41.8 \pm 0.1$ & $49 \pm 3$ & 72 \\
\hline DBS04 & $87 \pm 6$ & $36 \pm 14$ & $43 \pm 10$ & 73 \\
\hline DMABP01 & $77 \pm 9$ & $57 \pm 4$ & - & 77 \\
\hline DMABP02 & $74 \pm 8$ & $62 \pm 8$ & - & 78 \\
\hline DMABP03 & $88 \pm 8$ & $34 \pm 9$ & $37 \pm 9$ & 75 \\
\hline DMABP04 & $89 \pm 4$ & $23.4 \pm 0.3$ & $24 \pm 6$ & 76 \\
\hline DMABP05 & $47 \pm 6$ & $26 \pm 7$ & - & 75 \\
\hline DМАВР06 & $56 \pm 19$ & $36 \pm 7$ & - & 78 \\
\hline DМАBP07 & $69 \pm 9$ & $14 \pm 10$ & $22 \pm 6$ & 76 \\
\hline DМАBP08 & $67 \pm 13$ & $18 \pm 5$ & $22 \pm 13$ & 77 \\
\hline ITX01 & $64 \pm 7$ & $52 \pm 6$ & - & 76 \\
\hline ITX02 & $47 \pm 8$ & $61 \pm 6$ & - & 78 \\
\hline ITX03 & $69 \pm 3$ & $41 \pm 1$ & $59 \pm 7$ & 77 \\
\hline ITX04 & $94 \pm 2$ & $39 \pm 5$ & $42 \pm 9$ & 77 \\
\hline ITX05 & $57 \pm 4$ & $51 \pm 7$ & - & 76 \\
\hline ITX06 & $44 \pm 10$ & $37 \pm 7$ & - & 78 \\
\hline ITX07 & $69 \pm 4$ & $42 \pm 6$ & $65 \pm 8$ & 74 \\
\hline ITX08 & $75 \pm 12$ & $39 \pm 3$ & $44 \pm 6$ & 76 \\
\hline
\end{tabular}

Table A2. Overview of FTIR stretching and deformation vibrations in Durazane 1800 [38].

\begin{tabular}{ccc}
\hline Chemical Bonds & $\begin{array}{c}\text { Stretching Vibrations } \\
{\left[\mathbf{c m}^{-\mathbf{1}}\right]}\end{array}$ & $\begin{array}{c}\text { Deformation Vibrations } \\
{\left[\mathbf{c m}^{-\mathbf{1}}\right]}\end{array}$ \\
\hline $\mathrm{N}-\mathrm{H}$ & 3382 & 1176 \\
$\mathrm{C}-\mathrm{H}$ (vinyl) & 3046 & \\
$\mathrm{C}-\mathrm{H}$ in $\mathrm{CH}_{\mathrm{x}}\left(\mathrm{CH}_{3}\right.$ asymmetric $)$ & 2957 & \\
$\mathrm{C}-\mathrm{H}$ in $\mathrm{CH}_{\mathrm{x}}\left(\mathrm{CH}_{2}\right.$ asymmetric $)$ & 2902 & \\
$\mathrm{C}-\mathrm{H}$ in $\mathrm{CH}_{\mathrm{x}}(\mathrm{CH}$ asymmetric) & 2804 & 1596 \\
$\equiv \mathrm{Si}-\mathrm{H}$ & 2135 & 1400 \\
$\mathrm{C}=\mathrm{C}$ double bond in vinyl group & & 1257 \\
$\mathrm{CH} \mathrm{H}_{3}$ & & \\
$\equiv \mathrm{Si}-\mathrm{CH}_{3}$ & & \\
$\equiv \mathrm{Si}-\mathrm{CH} \mathrm{H}_{2}-\mathrm{CH} \mathrm{H}_{2}-\mathrm{Si} \equiv$ & $1180-1120$ & \\
$\equiv \mathrm{Si}-\mathrm{O}-\mathrm{S} \equiv$ & $1080-1040$ & \\
$\equiv \mathrm{Si}-\mathrm{N}-\mathrm{S} \equiv$ & & \\
$\equiv \mathrm{Si}-\mathrm{CH}=\mathrm{CH}_{2}$ & 950 & \\
\hline
\end{tabular}


(a)

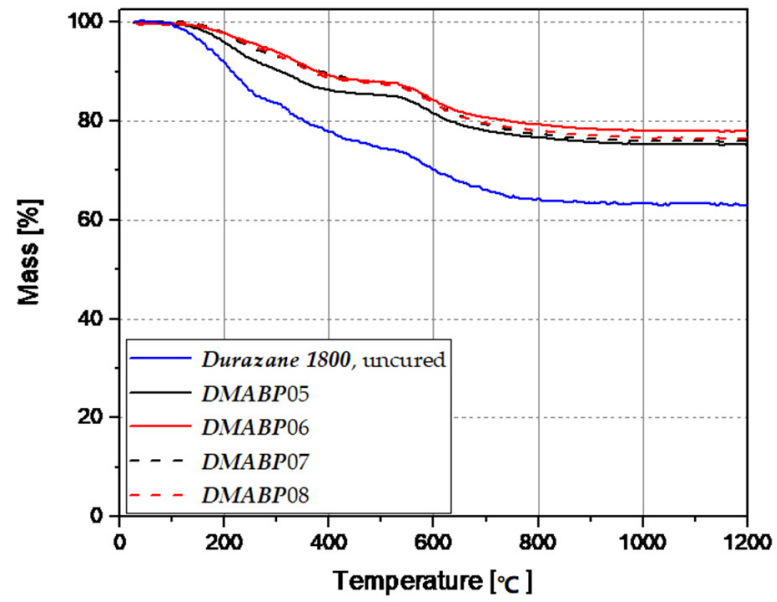

(b)

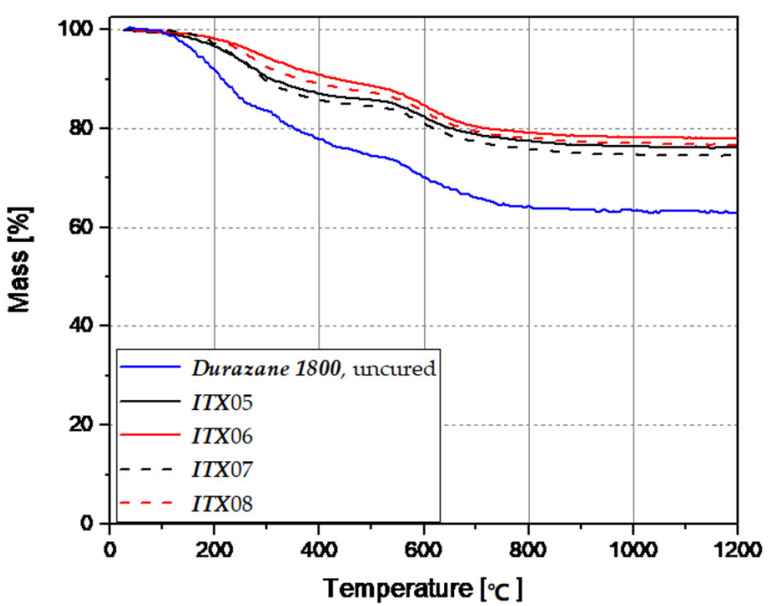

Figure A1. Thermograms of samples cured by an LED source $(\lambda=405 \mathrm{~nm})$ measured in nitrogen atmosphere: (a) DMABP0508 and (b) ITX05-08. The black curves are mixtures of Durazane 1800 with $1 \mathrm{wt} \%$ photoinitiator concentration and the red curves are mixtures of Durazane 1800 with $3 \mathrm{wt} \%$ PI concentrations. The dotted curves were cured in inert atmosphere and the non-dotted in ambient atmosphere. The blue curve belongs to pure uncured Durazane 1800 measured in nitrogen atmosphere.

(a)

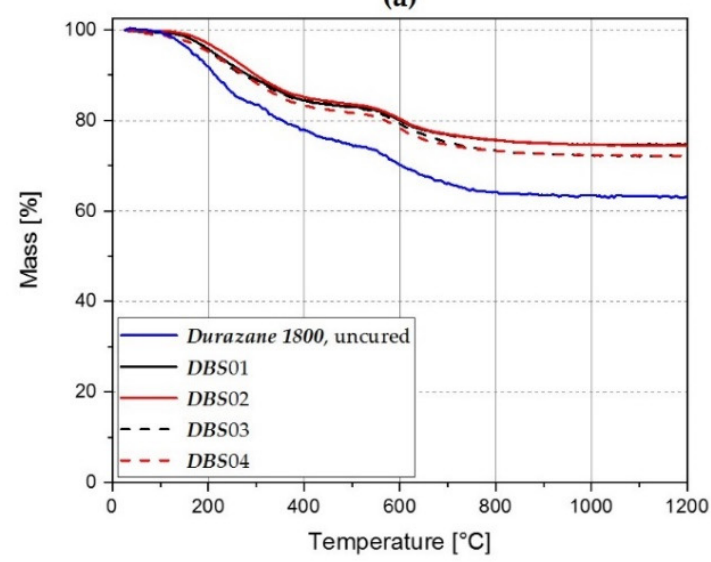

(b)

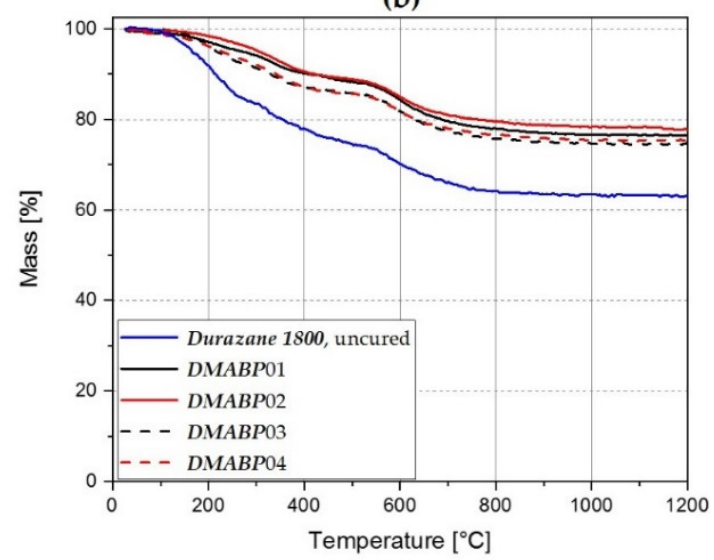

(c)

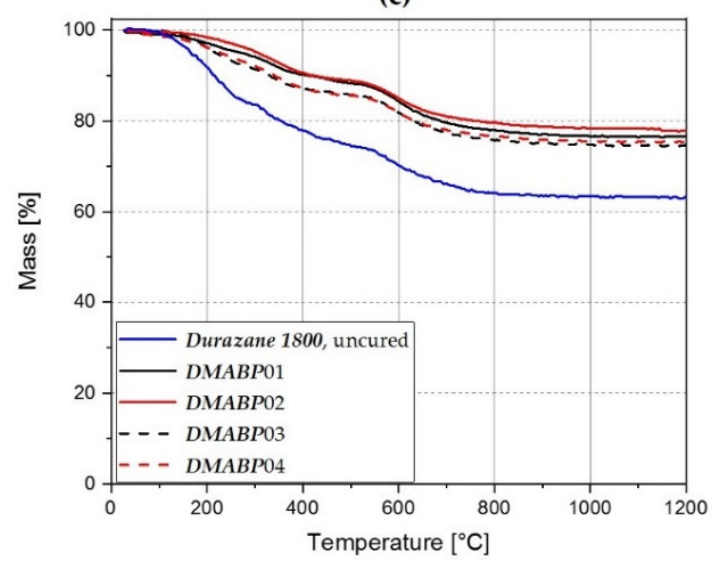

Figure A2. Thermograms of the samples cured by an LED source $(\lambda=385 \mathrm{~nm})$ measured in nitrogen atmosphere: (a) DBS01-04, (b) DMABP01-04, and (c) ITX01-04. The black curves are mixtures of Durazane 1800 with 1 wt \% photoinitiator concentration and the red curves are mixtures of Durazane $1800 \mathrm{with} 3 \mathrm{wt} \%$ PI concentration. The dotted curves were cured in inert atmosphere and the non-dotted in ambient atmosphere. The blue curve belongs to pure uncured Durazane 1800 measured in nitrogen atmosphere. 


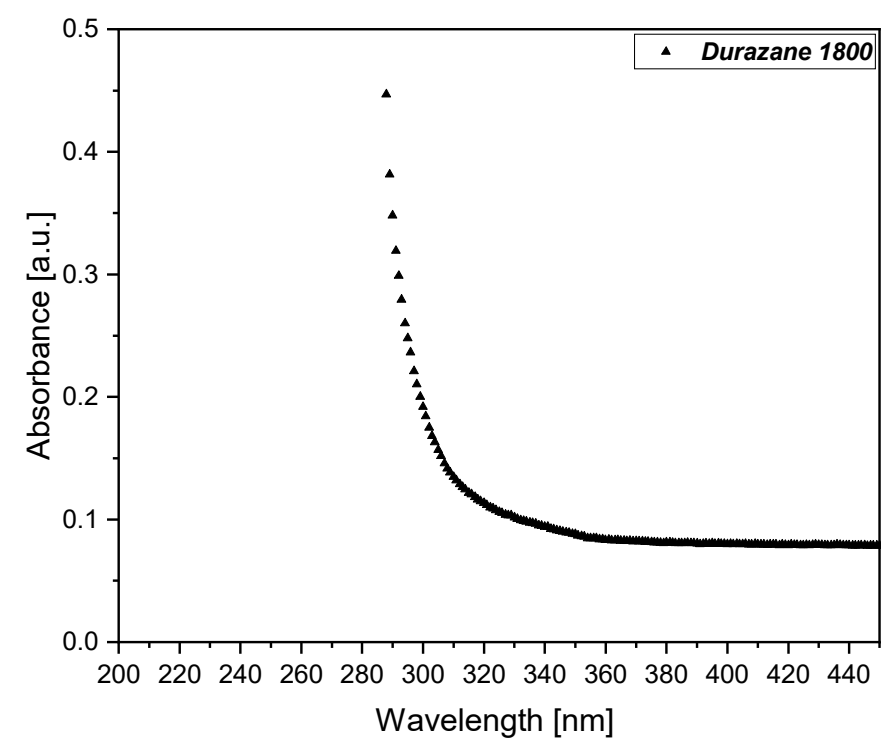

Figure A3. UV-VIS spectra of pure Durazane 1800.

\section{References}

1. Colombo, P.; Mera, G.; Riedel, R.; Sorarù, G.D. Polymer-Derived Ceramics: 40 Years of Research and Innovation in Advanced Ceramics: Polymer-Derived Ceramics. J. Am. Ceram. Soc. 2010, 93, 1805-1837. [CrossRef]

2. Barroso, G.; Döring, M.; Horcher, A.; Kienzle, A.; Motz, G. Polysilazane-Based Coatings with Anti-Adherent Properties for Easy Release of Plastics and Composites from Metal Molds. Adv. Mater. Interfaces 2020, 7, 1901952. [CrossRef]

3. Parchovianský, M.; Parchovianská, I.; Švančárek, P.; Motz, G.; Galusek, D. PDC Glass/Ceramic Coatings Applied to Differently Pretreated AISI441 Stainless Steel Substrates. Materials 2020, 13, 629. [CrossRef]

4. Fonblanc, D.; Lopez-Ferber, D.; Wynn, M.; Lale, A.; Soleilhavoup, A.; Leriche, A.; Iwamoto, Y.; Rossignol, F.; Gervais, C.; Bernard, S. Crosslinking chemistry of poly(vinylmethyl-co-methyl)silazanes toward low-temperature formable preceramic polymers as precursors of functional aluminium-modified Si-C-N ceramics. Dalton Trans. 2018, 47, 14580-14593. [CrossRef] [PubMed]

5. Kemp, J.W.; Hmeidat, N.S.; Compton, B.G. Boron nitride-reinforced polysilazane-derived ceramic composites via direct-ink writing. J. Am. Ceram. Soc. 2020, 103, 4043-4050. [CrossRef]

6. Xiao, J.; Jia, Y.; Liu, D.; Cheng, H. Three-dimensional printing of SiCN ceramic matrix composites from preceramic polysilazane by digital light processing. Ceram. Int. 2020, 46, 25802-25807. [CrossRef]

7. Kroke, E.; Li, Y.-L.; Konetschny, C.; Lecomte, E.; Fasel, C.; Riedel, R. Silazane derived ceramics and related materials. Mater. Sci. Eng. R Rep. 2000, 26, 97-199. [CrossRef]

8. Krüger, C.R.; Rochow, E.G. Polyorganosilazanes. J. Polym. Sci. A 1964, 2, 3179-3189. [CrossRef]

9. D'Elia, R.; Dusserre, G.; Del Confetto, S.; Eberling-Fux, N.; Descamps, C.; Cutard, T. Effect of dicumyl peroxide concentration on the polymerization kinetics of a polysilazane system. Polym. Eng. Sci. 2018, 58, 859-869. [CrossRef]

10. Guo, X.; Feng, Y.; Liu, Y.; Lin, X.; Zhang, Y.; Gong, H. Cross-linking behavior and dielectric properties of SiCN precursor. Ceram. Int. 2017, 43, 16866-16871. [CrossRef]

11. Ren, Z.; Gervais, C.; Singh, G. Preparation and structure of SiOCN fibres derived from cyclic silazane/poly-acrylic acid hybrid precursor. R. Soc. Open Sci. 2019, 6, 190690. [CrossRef]

12. Flores, O.; Schmalz, T.; Krenkel, W.; Heymann, L.; Motz, G. Selective cross-linking of oligosilazanes to tailored meltable polysilazanes for the processing of ceramic SiCN fibres. J. Mater. Chem. A 2013, 1, 15406-15415. [CrossRef]

13. Schulz, M.; Börner, M.; Göttert, J.; Hanemann, T.; Haußelt, J.; Motz, G. Cross Linking Behavior of Preceramic Polymers Effected by UV- and Synchrotron Radiation. Adv. Eng. Mater. 2004, 6, 676-680. [CrossRef]

14. Kong, J.; Fan, X.; Zhang, G.; Xie, X.; Si, Q.; Wang, S. Synthesis and UV-curing behaviors of novel rapid UV-curable polyorganosilazanes. Polymer 2006, 47,1519-1525. [CrossRef]

15. He, W.; Chen, L.; Peng, F. Coating formed by SiBCN single source precursor via UV-photopolymerization. Mater. Lett. 2017, 206, 121-123. [CrossRef]

16. Cramer, N.B.; Reddy, S.K.; Lu, H.; Cross, T.; Raj, R.; Bowman, C.N. Thiol-ene photopolymerization of polymer-derived ceramic precursors. J. Polym. Sci. Part Polym. Chem. 2004, 42, 1752-1757. [CrossRef]

17. Obmann, R.; Schörpf, S.; Gorsche, C.; Liska, R.; Fey, T.; Konegger, T. Porous polysilazane-derived ceramic structures generated through photopolymerization-assisted solidification templating. J. Eur. Ceram. Soc. 2019, 39, 838-845. [CrossRef]

18. Wang, X.; Schmidt, F.; Hanaor, D.; Kamm, P.H.; Li, S.; Gurlo, A. Additive manufacturing of ceramics from preceramic polymers: A versatile stereolithographic approach assisted by thiol-ene click chemistry. Addit. Manuf. 2019, 27, 80-90. [CrossRef]

19. Drobny, J.G. Radiation Technology for Polymers, 3rd ed.; CRC Press: Boca Raton, FL, USA, 2020; ISBN 978-0-367-18932-7. 
20. Schwalm, R. UV Coatings Basics, Recent Developments and New Applications; Elsevier: Amsterdam, The Netherland; London, UK, 2007; ISBN 978-0-08-046689-7.

21. Morlier, A.; Cros, S.; Garandet, J.-P.; Alberola, N. Structural properties of ultraviolet cured polysilazane gas barrier layers on polymer substrates. Thin Solid Films 2014, 550, 85-89. [CrossRef]

22. Kim, J.; Jang, J.H.; Kim, J.-H.; Park, K.; Jang, J.S.; Park, J.; Park, N. Inorganic Encapsulation Method Using Solution-Processible Polysilazane for Flexible Solar Cells. ACS Appl. Energy Mater. 2020, 3, 9257-9263. [CrossRef]

23. Tehfe, M.; Louradour, F.; Lalevée, J.; Fouassier, J.-P. Photopolymerization Reactions: On the Way to a Green and Sustainable Chemistry. Appl. Sci. 2013, 3, 490-514. [CrossRef]

24. Mucci, V.; Vallo, C. Efficiency of 2,2-dimethoxy-2-phenylacetophenone for the photopolymerization of methacrylate monomers in thick sections. J. Appl. Polym. Sci. 2012, 123, 418-425. [CrossRef]

25. Hu, L.-H.; Raj, R. Semiconductive Behavior of Polymer-Derived SiCN Ceramics for Hydrogen Sensing. J. Am. Ceram. Soc. 2015, 98, 1052-1055. [CrossRef]

26. Liew, L.-A.; Liu, Y.; Luo, R.; Cross, T.; An, L.; Bright, V.M.; Dunn, M.L.; Daily, J.W.; Raj, R. Fabrication of SiCN MEMS by photopolymerization of pre-ceramic polymer. Sens. Actuators Phys. 2002, 95, 120-134. [CrossRef]

27. Zhan, Y.; Grottenmüller, R.; Li, W.; Javaid, F.; Riedel, R. Evaluation of mechanical properties and hydrophobicity of roomtemperature, moisture-curable polysilazane coatings. J. Appl. Polym. Sci. 2021, 138, 50469. [CrossRef]

28. Günthner, M.; Schütz, A.; Glatzel, U.; Wang, K.; Bordia, R.K.; Greißl, O.; Krenkel, W.; Motz, G. High performance environmental barrier coatings, Part I: Passive filler loaded SiCN system for steel. J. Eur. Ceram. Soc. 2011, 31, 3003-3010. [CrossRef]

29. Parchovianský, M.; Petríková, I.; Švančárek, P.; Lenz Leite, M.; Motz, G.; Galusek, D. Passive filler loaded polysilazane-derived glass/ceramic coating system applied to AISI 441 stainless steel, part 2: Oxidation behavior in synthetic air. Int. J. Appl. Ceram. Technol. 2020, 17, 1675-1687. [CrossRef]

30. Mera, G.; Tamayo, A.; Nguyen, H.; Sen, S.; Riedel, R. Nanodomain Structure of Carbon-Rich Silicon Carbonitride Polymer-Derived Ceramics. J. Am. Ceram. Soc. 2010, 93, 1169-1175. [CrossRef]

31. Kim, K.; Ju, H.; Kim, J. Pyrolysis behavior of polysilazane and polysilazane-coated-boron nitride for high thermal conductive composite. Compos. Sci. Technol. 2017, 141, 1-7. [CrossRef]

32. Sideridou, I.; Tserki, V.; Papanastasiou, G. Effect of chemical structure on degree of conversion in light-cured dimethacrylate-based dental resins. Biomaterials 2002, 23, 1819-1829. [CrossRef]

33. Norrish Type II Reaction: (Norrish Type II Process, Norrish Type II Photoreaction, Yang Cyclization). In Comprehensive Organic Name Reactions and Reagents; John Wiley \& Sons, Inc.: Hoboken, NJ, USA, 2010; ISBN 978-0-470-63885-9.

34. Calbo, L.J. (Ed.) Handbook of Coatings Additives; M. Dekker: New York, NY, USA, 1987; ISBN 978-0-8247-7561-2.

35. Bill, J.; Seitz, J.; Thurn, G.; Dürr, J.; Canel, J.; Janos, B.Z.; Jalowiecki, A.; Sauter, D.; Schempp, S.; Lamparter, H.P.; et al. Structure Analysis and Properties of Si-C-N Ceramics Derived from Polysilazanes. Phys. Status Solidi A 1998, 166, 269-296. [CrossRef]

36. Reschke, S.; Haluschka, C.; Riedel, R.; Lenčéš, Z.; Galusek, D. In situ generated homogeneous and functionally graded ceramic materials derived from polysilazane. J. Eur. Ceram. Soc. 2003, 23, 1963-1970. [CrossRef]

37. Chavez, R.; Ionescu, E.; Balan, C.; Fasel, C.; Riedel, R. Effect of ambient atmosphere on crosslinking of polysilazanes. J. Appl. Polym. Sci. 2011, 119, 794-802. [CrossRef]

38. Arkles, B.; Larson, G.L. Silicon Compounds: Silanes and Silicones; Gelest: Morrisville, PA, USA, 2013; ISBN 978-0-578-12235-9.

39. Dargère, N.; Bounor-Legaré, V.; Boisson, F.; Cassagnau, P.; Martin, G.; Sonntag, P.; Garois, N. Hydridosilazanes hydrolysiscondensation reactions studied by 1H and 29Si liquid NMR spectroscopy. J. Sol. Gel. Sci. Technol. 2012, 62, 389-396. [CrossRef]

40. Müller, S.; de Hazan, Y.; Penner, D. Effect of temperature, humidity and aminoalkoxysilane additive on the low temperature curing of polyorganosilazane coatings studied by IR spectroscopy, gravimetric and evolved gas analysis. Prog. Org. Coat. 2016, 97, 133-145. [CrossRef]

41. Bauer, F.; Decker, U.; Dierdorf, A.; Ernst, H.; Heller, R.; Liebe, H.; Mehnert, R. Preparation of moisture curable polysilazane coatings. Prog. Org. Coat. 2005, 53, 183-190. [CrossRef]

42. Günthner, M.; Wang, K.; Bordia, R.K.; Motz, G. Conversion behaviour and resulting mechanical properties of polysilazane-based coatings. J. Eur. Ceram. Soc. 2012, 32, 1883-1892. [CrossRef]

43. Greil, P. Polymer Derived Engineering Ceramics. Adv. Eng. Mater. 2000, 2, 339-348. [CrossRef]

44. Barroso, G.; Li, Q.; Bordia, R.K.; Motz, G. Polymeric and ceramic silicon-based coatings-A review. J. Mater. Chem. A 2019, 7, 1936-1963. [CrossRef]

45. Green, W.A. Industrial Photoinitiators: A Technical Guide; CRC Press: Boca Raton, FL, USA, 2010; ISBN 978-1-4398-2745-1. 